\title{
1 Measuring water exchange across the blood-brain barrier using MRI
}

2 Ben R Dickie ${ }^{1}$, Geoff JM Parker ${ }^{2,3}$, Laura M Parkes ${ }^{1}$

3 1. Division of Neuroscience and Experimental Psychology, University of Manchester, Oxford

4 Road, Manchester, M13 9PT, United Kingdom. 2. Bioxydyn Limited, Manchester, M15 6SZ,

5 United Kingdom. 3. Centre for Medical Image Computing, Department of Computer Science

6 and Department of Neuroinflammation, University College London, London, United

7 Kingdom.

9 Corresponding author

10 Email: ben.dickie@manchester.ac.uk

11 Address: Room 3.07A, Zochonis Building, Brunswick Street, Manchester, M13 9PT

13 No of pages: 71

14 No of figures: 4

15 No of tables: 6

16 Keywords: blood-brain barrier dysfunction, water permeability, water exchange, magnetic

17 resonance imaging, aquaporin

\section{Abstract}

19 The blood-brain barrier (BBB) regulates the transfer of solutes and essential nutrients into

20 the brain. Growing evidence supports BBB dysfunction in a range of acute and chronic brain

21 diseases, justifying the need for novel research and clinical tools that can non-invasively

22 detect, characterize, and quantify BBB dysfunction in-vivo. Many approaches already exist

23 for measuring BBB dysfunction in man using positron emission tomography and magnetic

24 resonance imaging (e.g. dynamic contrast-enhanced-MRI measurements of gadolinium

25 leakage). This review paper focusses on MRI measurements of water exchange across the

26 BBB, which occurs through a wide range of pathways, and is likely to be a highly sensitive 
27 marker of BBB dysfunction. Key mathematical models and acquisition methods are

28 discussed for the two main approaches: those that utilize contrast agents to enhance

29 relaxation rate differences between the intravascular and extravascular compartments and

30 so enhance the sensitivity of MRI signals to BBB water exchange, and those that utilize the

31 dynamic properties of arterial spin labelling to first isolate signal from intravascular spins and

32 then estimate the impact of water exchange on the evolving signal. Data from studies in

33 healthy and pathological brain tissue are discussed, in addition to validation studies in

34 rodents. 
51 Table of Contents

1. Introduction

2. Evidence for limited BBB water exchange

3. Definitions of physical parameters governing BBB water exchange

4. The effect of inter-compartmental water exchange on measured relaxation rates and diffusion coefficients

5. Modelling the effects of BBB water exchange on MRI signals

5.1 Exchange models for contrast agent based measurements

5.2 Exchange models for arterial spin-labelling based measurements

6. MRI approaches for quantifying BBB water exchange 
6.3 Approaches based on injection of MRI-detectable water tracers

6.3.1 Indirect detection of ${ }^{17} \mathrm{O}$-labeled water via its effect on ${ }^{1} \mathrm{H} \mathrm{T}_{2}$

6.3.2 Indirect detection of ${ }^{2} \mathrm{H}$-labeled water by proton replacement

7. Summary of published results

7.1 Water exchange across the BBB in healthy brain tissue

7.2 Water exchange across the BBB in disease

7.2.1 Water exchange across the BBB in stroke

7.2.2 Water exchange across the BBB in neurodegeneration

80

7.2.3 Water exchange across the BBB in obstructive sleep apnea

81

7.2.4 Water exchange across the BBB in multiple sclerosis (MS)

82

7.2.5 Water exchange across the BBB in brain tumours

83

84

85

86

8. Validity of a two-site model for BBB water exchange

87

9. Physiological specificity of BBB water exchange measurements

88

10. Conclusion

89

90

91

92 


\section{Introduction}

The blood-brain barrier (BBB) plays a crucial role in the maintenance of neuronal function and health. Its main functions include protecting the brain from blood-borne toxins and pathogens, regulating transport of solutes into the brain, and clearing metabolic waste and other neurotoxic compounds into the bloodstream. In contrast to peripheral tissues, endothelial cells in the brain are sealed together by specialized tight junction proteins. These proteins prevent free paracellular diffusion (i.e. diffusion through gaps between endothelial cells) of particles from the bloodstream into the brain. Furthermore, brain endothelial cells are surrounded by cellular and membrane components including pericytes, basement membrane, perivascular channels, and astrocyte endfeet, each forming additional physical barriers to diffusion [1-3] (Figure 1). Solutes required by the brain for cellular metabolism, repair, and maintenance, cross the BBB through specialized proteins located on endothelial

107 cell membranes. Rapid transcellular diffusion across the endothelial cell membrane itself is possible only for lipid-soluble substances such as non-polar molecular gases (e.g. $\mathrm{O}_{2}$ and $\mathrm{CO}_{2}$ ) and low molecular weight alcohols (e.g. ethanol, butanol).

110 Blood-brain barrier dysfunction occurs in many conditions including ageing, stroke, cancer,

111 multiple sclerosis, and neurodegeneration, and often occurs concomitantly with neuro-

112 inflammation. Non-invasive methods to probe BBB dysfunction in-vivo are needed to

113 understand the impact of these alterations on the pathogenesis and progression of these

114 conditions. Most current approaches aim to use imaging methods to track the uptake of

115 intravenously injected tracers as they pass from the blood stream into the brain. In animal

116 models, 2-photon microscopy can monitor leakage of fluorescent dyes across the BBB, but

117 the field of view is small, and scanning depth is limited to a few millimetres below the cortical

118 surface. Photoacoustic imaging can bridge the gap between microscopic and macroscopic

119 scales, enabling imaging of dyes or probes with specific absorption characteristics (e.g. 
120 Evans blue) at greater depths than fluorescence based imaging systems [4], but still does

121 not have adequate penetration for human brain use, and is challenging to quantify. Positron

122 emission tomography (PET) and magnetic resonance imaging (MRI) have lower spatial

123 resolution, but can image the entire brain using quantitative methods, enabling regional

124 assessment. Importantly, they can be applied to humans, as well as rodents.
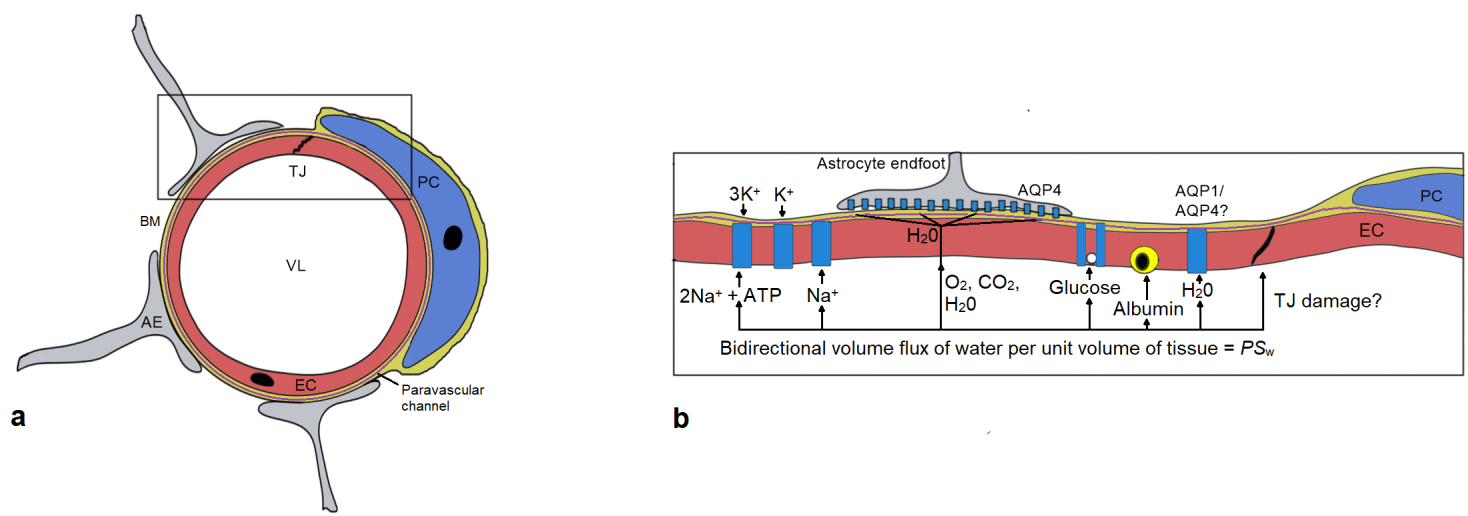

b

Figure 1. The blood-brain barrier (BBB). a The vessel lumen (VL) is formed by endothelial cells (EC) sealed together by tight junction (TJ) proteins. Surrounding the ECs is a basement membrane composed of extracellular matrix proteins including laminin, fibrin, and collagen. Paravascular pathways of the glymphatic system are embedded within this membrane. Astrocyte endfeet (AE) and pericytes (PC) surround the ECs and play crucial roles in neurovascular coupling, as well as forming physical barriers to diffusion across the BBB. $\mathbf{b}$ An enlarged diagram of the blood-brain interface from the box in a. Long-term preservation of an optimal ionic and nutrient-rich environment for synaptic and neural function is achieved by specific ion channels and transporters. Ion channels facilitate passive diffusion of $\mathrm{K}^{+}$and $\mathrm{Na}^{+}$ions along electrochemical gradients. Ion pumps actively transport ions against an electrochemical gradient (e.g., the $\mathrm{Na}^{+}-\mathrm{K}^{+}$-ATPase ion pump) and work in combination with ion channels to maintain trans-endothelial ion concentration differences. Gases (in particular $\mathrm{O}_{2}, \mathrm{CO}_{2}$ ) and other lipophilic substances diffuse freely across the endothelial cell membranes. Diffusion of water also occurs across the endothelial membrane, but is very slow in comparison. Larger hydrophilic solutes required for brain functioning (i.e., metabolites, vitamins, nucleotides, simple sugars) pass through specialized proteins located on the luminal and abluminal cell membranes which act to accelerate delivery. Simple sugars such as glucose are transported into the brain by specialized carrier-mediated proteins such as GLUT1. Large circulating proteins (e.g. albumin, insulin) and polysaccharides, which are often of greater dimensions than transmembrane channels and transporters themselves, pass across the BBB by receptor mediated transcytosis. Carrier and receptor mediated transport are restricted to the specific molecules they are encoded for. Tight junction proteins seal the endothelial cells together but this location between cells may provide a route for passive diffusion of molecules into the brain if the proteins are damaged or expression downregulated. Water movement can occur through all these pathways, and possibly through dedicated aquaporin channels located on the endothelial cells (AQP1/AQP4). Water transfer therefore has the potential to be altered in a range of BBB pathologies. In this diagram, all transmembrane proteins have been depicted as bridging the luminal-abluminal gap entirely; however, in reality these proteins exist on luminal and/or luminal membranes and transport solutes into and out of the endothelial cell itself. Together luminal and abluminal proteins act to move solutes from blood to brain or vice- versa. 
156 PET has the potential to provide highly specific information on the activity of BBB

157 transporters (e.g. GLUT1 using ${ }^{18}$ F-Fluro-2-deoxy-2-D-glucose [5] or P-gp using

$158\left[{ }^{11}\right.$ C]verapamil [6]). Accurate quantification requires arterial or venous blood sampling, and

159 repeat scanning in at-risk healthy populations (e.g. for longitudinal ageing and dementia

160 studies) is difficult to justify due to cumulative doses of ionising radiation. MRI has the

161 potential to spatially map BBB transporter function due to recent advances in molecular

162 imaging sequences (e.g. chemical-exchange saturation transfer imaging). However, these

163 methods are still in their infancy and lack validation [7].

164 MRI measurements in clinical use are currently limited to measuring paracellular leakage of

165 low molecular weight gadolinium contrast agents. Unfortunately, these tracers are not

166 specifically designed to probe BBB function, are thought to cross the BBB via paracellular

167 routes only, and leak very slowly unless damage to the tight junctions or endothelial cell

168 membrane is severe. While this is useful to help differentiate severely disrupted from healthy

169 BBB, e.g. in stroke or oncology, these tracers are not well suited for identifying abnormal

170 tissue in pathologies where BBB breakdown is more subtle (e.g. that due to ageing and

171 neurodegenerative diseases), or where dysfunction alters the activity of specific transporters

172 through which the contrast agent does not pass. Due to the low amplitude of signal change

173 detected using these methods, factors such as partial volume errors, Gibbs ringing, signal

174 drift, patient motion, arterial input function definition errors, and kinetic model inaccuracy can

175 confound measurements [8-10]. It is also possible that such tracers do not leak across the

176 BBB at all until paracellular pores reach a certain size $[11,12]$.

177 While it has long been recognised that water does not diffuse freely across the BBB [13-18],

178 the idea that water could be used to probe BBB function has only recently been proposed.

179 Recent interest in novel approaches to probe BBB water permeability have been triggered

180 by safety concerns relating to accumulation of gadolinium contrast media in the brain, in

181 addition to a desire to find more sensitive approaches for studying subtle BBB alterations. In 
182 addition to potential safety benefits, the use of water to study BBB function has the following

183 key differences compared to other tracers:

184 1. At equilibrium in the healthy brain, water is transported across the BBB by both passive (diffusive) and active mechanisms (through co-transporters and uniporters) [19], potentially providing sensitivity to a wide range of BBB pathologies.

2. Due to the small size of a water molecule, changes that affect diffusive permeability of the BBB are likely to be detectable at an earlier stage of disease, when damage is more subtle.

3. Water has its own transport protein (aquaporins), which cannot be probed using other tracers.

192 A number of MRI techniques to measure BBB water exchange have been proposed. These can be grouped primarily into those that utilise an exogenous contrast agent (e.g. contrast-

194 enhanced MRI) and those that do not (e.g. arterial spin labelling (ASL) MRI). This review

195 summarises evidence for limited water exchange across the BBB, discusses theory and

196 modelling relevant for MRI BBB water exchange measurements; and discusses MRI

197 methods for measuring BBB water exchange, including their limitations, technical and

198 biological validation, and applications to healthy and diseased brain tissue.

\section{2. Evidence for limited BBB water exchange}

200 If a molecule has very high BBB permeability, the fraction of these molecules that pass across the BBB ('extraction fraction'), either by passive diffusion or active transport, during a single pass will be close to 1 . This is because, as the permeability of the barrier to a

203 particular molecule increases, the probability that the molecule will exchange across the

204 barrier before it leaves the capillary bed also increases. In the limit that the permeability is 205 very high relative to the blood velocity, the probability that a particle entering the capillary bed will exchange across the BBB prior to exiting approaches 1. 
207 Extraction fractions $(E)$ less than 1 indicate that the molecule is not freely diffusible or rapidly

208 transported, and that barriers (e.g. tight junctions or lack of transporters) limit passage from

209 blood to brain. If cerebral blood flow (CBF; defined as $f$ ) is also known, then the permeability-

210 surface area product of the BBB to the molecule of interest $(P S)$ can also be calculated

211 using the Renkin-Crone equation [20,21]:

$$
P S=-\ln (1-E) f
$$

212 The PS product of a molecule in this context describes its flux across the BBB, from blood to

213 brain, and is hence a useful physiological parameter describing the delivery of a molecule to

214 the brain. As its name implies, it is a function of both the permeability of the barrier $(P)$ and

215 the surface area of exchange vessels $(S) . P$ will depend on the function and integrity of the

216 blood-brain barrier. $S$ depends on the diameter and density of exchange vessels.

217 Since the 1970's a range of methods to measure the extraction fraction and PS of water

$218\left(P S_{w}\right)$ have been proposed, and applied in rodents and larger mammals, including humans.

219 A summary of key results which inform our current understanding of BBB water transport are

220 given below.

221 The extraction fraction of water is less than 1 [13-18]. The extraction fraction of water is

222 lower in rodents $[14,16,17]$ than in monkeys [13] and humans $[15,18]$. This is mainly

223 attributable to inter-species differences in $C B F$, which can be 2-4 greater in rodents than

224 humans. Inter-species variations in extraction do not appear to depend on $P S_{\mathrm{w}}[13,16-$

225 18,22]. Extraction of water across the BBB decreases with increased arterial $\mathrm{CO}_{2}$ tension,

226 mainly due to increased $C B F[13,14,23] . P S_{w}$ increases with arterial $C_{2}$ tension, which acts

227 to partially offset the effects of increased CBF on extraction [14,17]. Anaesthesia increases

228 extraction fraction, due to large reductions in CBF. $P S_{\mathrm{w}}$ also decreases but to a lesser

229 degree [16], indicating that rodent studies that use anaesthesia may underestimate $P S_{\mathrm{w}}$

230 occurring under normal physiological conditions. $C B F$ is regionally correlated with $P S_{w}[18]$.

\section{3. Definitions of physical parameters governing BBB water exchange}


232 When measuring water exchange across the BBB using MRI, key parameters of interest

233 include volume and magnetisation fluxes, intra- and extravascular magnetisation, intra- and

234 extravascular water population fractions, water exchange rates, and water residence times.

235 The definitions and symbols used for these quantities vary widely between studies,

236 particularly between fields of contrast-enhanced MRI and arterial spin labelling MRI. In this

237 review, we attempt to use consistent nomenclature to bridge the gap between these fields,

238 (Table 1) which we hope will help improve standardisation for future work in this area.

239 We begin by defining equilibrium and non-equilibrium water exchange kinetics. Equilibrium

240 water exchange describes a system for which the influx and efflux of water across the BBB

241 are equal (i.e., zero net flux). Non-equilibrium or osmotic water exchange is that which leads

242 to unidirectional movement of water (i.e., finite net flux). This review considers measurement

243 of equilibrium BBB water exchange only.

244 Under equilibrium water exchange conditions, the volume of water moving from blood to 245 brain per unit volume of tissue (also known as the permeability surface area product, $P S_{\mathrm{w}, \text { in }}$ $246\left[\mathrm{~mL} \mathrm{~min}^{-1} \mathrm{~mL}^{-1}\right]$ ) is by definition equal to the volume flux of water moving from brain to blood $247\left(P S_{\mathrm{w}, \text { out, }}\left[\mathrm{mL} \mathrm{min}^{-1} \mathrm{~mL}^{-1}\right]\right)$ :

$$
P S_{w, \text { in }}=P S_{w, \text { out }}
$$

248 When placed in an external magnetic field, the magnetic moments associated with each

249 water molecule become preferentially aligned with the field, creating a net bulk longitudinal

250 magnetisation. When fully relaxed (i.e. at equilibrium), the bulk magnetisation in each

251 compartment is proportional to its water content, enabling water population fractions of each

252 compartment to be defined. For a simple two-site exchange system comprising blood and

253 extravascular spaces (Figure 2$)$ the population fractions of water in each of these spaces $\left(p_{b}\right.$

$254\left[\mathrm{~mL} \mathrm{~mL}^{-1}\right]$ and $p_{e}\left[\mathrm{~mL} \mathrm{~mL}^{-1}\right]$, respectively) are given by:

$$
p_{b}=\frac{M_{0, b}}{M_{0, b}+M_{0, e}}
$$




$$
p_{e}=\frac{M_{0, e}}{M_{0, b}+M_{0, e}}
$$

256 where $M_{0, b}$ and $M_{0, e}$ are the equilibrium longitudinal magnetisations in the blood and 257 extravascular spaces, respectively. Because both water and contrast agent have limited 258 permeability across the endothelial cell membrane itself, we consider water contained within the endothelial cells to be part of the extravascular compartment. The blood compartment is 260 comprised of all water within the vessel lumen, including that within red blood cells and any 261 other non-plasma constituents. The sum of these water population fractions is unity:

$$
p_{b}+p_{e}=1
$$

262 When longitudinal magnetisation is fully relaxed, the influx and efflux of magnetisation $(\mathrm{J} ; \mathrm{J}]$ $263=($ magnetisation $\left.\left.) \min ^{-1}\right)\right)$ at the BBB are equal and given by:

$$
\begin{gathered}
J_{\text {in }}=J_{\text {out }} \\
k_{\text {in }} M_{0, b}=k_{\text {out }} M_{0, e}
\end{gathered}
$$

264 where $k_{\text {in }}\left[\mathrm{min}^{-1}\right]$ and $k_{\text {out }}\left[\mathrm{min}^{-1}\right]$ are the first-order exchange rate constants governing this exchange. Dividing both sides of equation 7 by the total tissue equilibrium magnetisation $M_{0, t}$ $266=M_{0, \mathrm{~b}}+M_{0, \mathrm{e}, \text { gives: }}$

$$
k_{\text {in }} p_{b}=k_{\text {out }} p_{e}
$$

$267 k_{\text {in }}$ and $k_{\text {out }}$ are often expressed as their inverse, the water residence or pre-exchange

268 lifetimes, $\tau_{\mathrm{b}}=1 / k_{\text {in }}[\mathrm{min}]$ and $\tau_{\mathrm{e}}=1 / k_{\text {out }}[\mathrm{min}]$. These characteristic times describe the mean

269 time spent by each water molecule before exchanging across the BBB.

270 Equation 8 encapsulates a key property of equilibrium transmembrane water exchange. That

271 is, that while the volume fluxes of water are the same in both directions across the

272 membrane, the rate constants $k_{\text {in }}$ and $k_{\text {out }}$ are not, unless the water population fractions $p_{\mathrm{b}}$

273 and $p_{\mathrm{e}}$ are equal. If the volumes of two exchanging compartments are unequal, then the 
275 maintain equal bidirectional volume fluxes. Since the blood compartment is smallest, water

276 molecules in the blood compartment must on average exchange across the BBB with a

277 higher probability than water molecules in the extravascular compartment (i.e. $k_{\text {in }}>k_{\text {out }}$ ).

278 The magnetisation influx $\left(k_{i n} M_{0, b}\right)$, can be written in terms of $P S_{\mathrm{w}}$ by dividing by the

279 magnetisation density in blood $\left(\rho=M_{0, b} / V_{b}\right)$ and the tissue volume, $V_{\mathrm{T}}$ :

$$
P S_{w}=\frac{k_{i n} M_{0, b}}{\rho V_{T}}=k_{i n} \frac{V_{b}}{V_{T}}=k_{i n} v_{b}
$$

where $v_{\mathrm{b}}$ is the fractional blood volume.

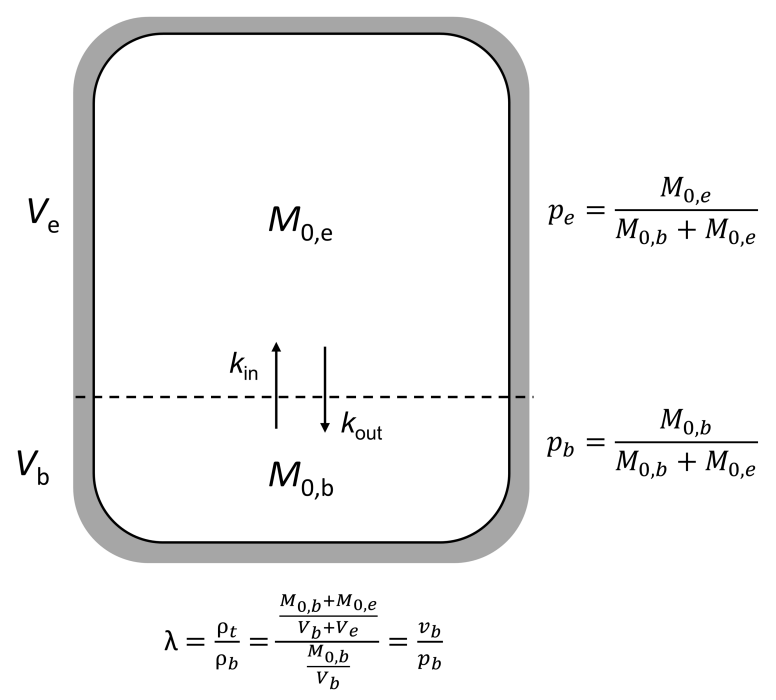

Figure 2. A two-site exchange system consisting of intravascular (bottom) and extravascular (top) spaces with absolute volumes $V_{b}$ and $V_{e}$ respectively. The entire volume including both intravascular and extravascular spaces is denoted as 'tissue' throughout this review. Water (magnetisation) exchanges between intravascular and extravascular spaces with rates $k_{\text {in }}$ and $k_{\text {out. }}$. Flow of magnetisation into and from the intravascular space is ignored for simplicity, but would be required to accurately describe the system in certain applications (e.g. ASL). Both spaces are composed of water-accessible (white) and water-inaccessible volumes (grey). Water-accessible volumes are detectable by MRI and have relative volumes $p_{\mathrm{b}}$ and $p_{\mathrm{e}}\left(=1-p_{\mathrm{b}}\right)$. Water-inaccessible volumes are invisible to MRI, and may differ in size between intravascular and extravascular spaces. The fraction of total equilibrium magnetisation in the intravascular space, $p_{b}$, may not therefore necessarily equal the blood volume fraction, $v_{b}$. This causes difficulty when calculating parameters that require knowledge of the blood volume, for example the permeability surface area product $\left(P S_{w}\right)$, where the surface area is defined over the blood volume, not the surface area of the water-accessible space. The tissue-blood partition coefficient, $\lambda$, describes the ratio of magnetisation density in the entire voxel to that of the intravascular volume, and converts $p_{\mathrm{b}}$ to $v_{\mathrm{b}}$. Since $\lambda$ is difficult to measure, it is generally assumed to be invariant across brain regions and subjects. Errors in this assumption will translate directly into errors in $P S_{\mathrm{w}}$. Estimates of $\lambda$ are not required to estimate the rate constants $k_{\text {in }}$ and $k_{\text {out. }}$ 
300 4. The effect of inter-compartmental water exchange on measured relaxation rates 301 and diffusion coefficients

302 The millimetre spatial resolution of MRI means measured signals are often composed of 303 contributions from multiple distinct microscopic 'water exchanging' compartments. If water 304 exchanges rapidly between these compartments, the compartments themselves are well305 mixed, and then observed relaxation rates and diffusion coefficients will appear to arise from 306 a single well mixed compartment (Figure 3a). This is because each water molecule will sample each compartment during the measurement time, and will experience relaxation and

308 diffusion environments that are an average of the multi-compartment system, weighted by

309 their relative volumes. Conversely, if water exchange is slow, water from each individually

310 well-mixed compartment will give rise to distinct signal contributions characterised by the

311 compartmental relaxation and diffusion properties (Figure 3b). For intermediate exchange

312 between compartments, water will experience some averaging effects, but this will not be

313 complete. Each compartment will give rise to distinct signal contributions but these will be

314 dependent on the exchange rate itself (Figure 3c). When measuring BBB water exchange,

315 the primary aim is to quantify the water exchange rates, and possibly water fluxes, between

316 the intra- and extravascular spaces. Ideally, water exchange between sub-compartments of

317 these spaces e.g. between plasma and red-blood cells, or neurones/astrocytes and

318 interstitial fluid, is normally assumed to be fast or the sub-compartments negligibly small,

319 such that a tissue voxel can be treated as a two-site exchange system, instead of a three-,

320 four-, or $\mathrm{N}$-site exchange system. In this case, the problem becomes one of distinguishing

321 the amplitudes (i.e., apparent volume fractions) and decay rates (i.e., apparent relaxation

322 rates or apparent diffusivities) of two distinct signal contributions; those arising from

323 intravascular and extravascular compartments. Because the signal decay rates of these

324 contributions depend on the exchange rates and the intrinsic relaxation rates, diffusivities, 


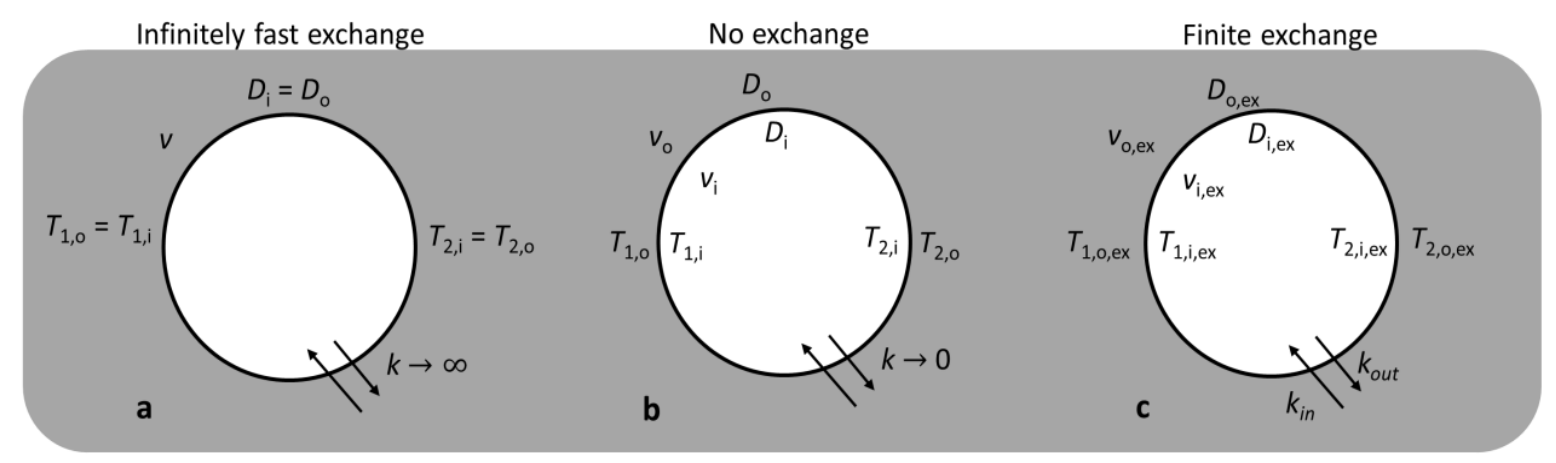

Figure 3. Water exchange across cell membranes. a When water exchange across a membrane is very fast, and each compartment is well-mixed, internal and external relaxation rates and diffusion coefficients become averaged together, resulting in a single $T_{1}, T_{2}$ and $D$ for both compartments. Under these conditions the individual compartment volumes cannot be distinguished. $\mathbf{b}$ When exchange across a membrane is slow or zero, and each compartment is well mixed, water relaxes and diffuses as a multi-component system with intrinsic relaxation times $\left(T_{1, i}, T_{1,0}, T_{2, i}, T_{2,0}\right)$ and apparent diffusion coefficients $\left(D_{0}, D_{\mathrm{i}}\right)$. If the relaxation rates or diffusivities can be distinguished from one another in the presence of experimental noise, the true volume fractions $v_{0}$ and $v_{i}$ can be measured, as these will be determined by the relative magnitudes of the compartmental signal contributions. c When exchange across a membrane is finite, water also relaxes and diffuses as a multi-component system. However, the measured relaxation times, diffusion coefficients, and fractional volumes are now dependent on the exchange rates $k_{\text {in }}$ and kout.

\section{5. Modelling the effects of BBB water exchange on MRI signals}

329 We have so far described the fundamental physiological properties governing water

330 exchange between intravascular and extravascular compartments, and how these properties

331 affect the nuclear magnetic resonance (NMR) properties of brain tissue. To describe how

332 these properties translate to MRI signal intensities, the temporal (and possibly spatial)

333 evolution of magnetisation in each compartment must be modelled. In all that follows,

334 transcytolemmal water exchange (i.e., water exchange between plasma and red-blood cells,

335 and between interstitial fluid and brain cells) is assumed to be infinitely fast.

336 The form of the mathematical model used to describe compartmental signal intensities must

337 take into account the experimental method used. To date, available methods can be broadly

338 categorised into contrast agent based, and contrast agent free (e.g. arterial spin labelling)

339 approaches. In contrast agent based approaches, an intravascular contrast agent is 
340 introduced into the blood pool to increase intravascular-extravascular $T_{1}$ differences.

341 Because $T_{1}$ interactions are short range, any changes in the $T_{1}$ of the extravascular

342 compartment can be attributed to trans-BBB water exchange. In contrast agent free

343 approaches, arterial spin labelling is used to tag capillary magnetisation, followed by a $T_{1}$,

$344 T_{2}$, or diffusion-weighted readout, which, because of compartmental differences in $T_{1}, T_{2}$,

345 and $D$, encodes the compartmentalisation of tagged magnetisation as a function of time. By

346 measuring the location of tagged spins as the label is exchanging, the exchange rate can be

347 determined. The following sections describe the models used to describe MRI signals

348 measured using these methods.

3495.1 Exchange models for contrast agent based measurements

350 Contrast agent based measurements of water exchange were proposed in the 1970s for

351 quantifying water exchange rates across red-blood cells in-vitro [24,25]. An extracellular

352 paramagnetic contrast agent $\left(\mathrm{Mn}^{2+}\right)$ that is unable to cross the red-blood cell membrane was

353 introduced into the plasma of blood, and its effect on intracellular water due to exchange

354 deduced via measurements of $T_{2}$. Schwarzbauer et al first adapted this method for in-vivo

355 measurements of BBB water exchange [26]. An intravascular contrast agent was introduced

356 into the blood pool via intravenous injection and its effect on the relaxation of extravascular

357 water due to BBB water exchange inferred.

359 In the experiments by Schwarzbauer et al. [26] and resulting work that followed [27-31], the

360 effect of exchange was quantified by measuring the effect on $T_{1}$, not $T_{2}$ as in the earlier red-

361 blood cell studies.

362 Factors other than the exchange rate also contribute to extravascular $T_{1}$ and must be

363 accounted for during modelling, including the intrinsic $T_{1}$ of the intravascular space (which is

364 now a function of contrast agent concentration), and the blood water population fraction. To

365 distinguish the effects of exchange from these other sources, $T_{1}$ relaxation rate 
measurements must be made for at least 3 contrast agent concentrations (including $0 \mathrm{mM}$ )

367 and in a location containing only blood (e.g. regions of interest in a large artery or vein).

368 The evolution of intravascular and extravascular magnetisation occurring during contrast

369 agent based water exchange measurements can be described using a two-site exchange

370 model via the Bloch McConnell equations [32]:

$$
\frac{d}{d t} M_{b}(t)=\frac{M_{0, b}-M_{b}(t)}{T_{1, b}}-k_{\text {in }} M_{b}(t)+k_{o u t} M_{e}(t)
$$

371

$$
\frac{d}{d t} M_{e}(t)=\frac{M_{0, e}-M_{e}(t)}{T_{1, e}}+k_{\text {in }} M_{b}(t)-k_{\text {out }} M_{e}(t)
$$

$$
M_{t}(t)=M_{b}(t)+M_{e}(t)
$$

373 where $M_{0, \mathrm{~b}}, M_{0, \mathrm{e}}, T_{1, \mathrm{~b}}$, and $T_{1, \mathrm{e}}$ are the equilibrium longitudinal magnetisations and intrinsic

$374 T_{1}$ relaxation times for intravascular and extravascular water respectively. $k_{\text {in }}$ and $k_{\text {out }}$ are the 375 water exchange rate constants into and out of the extravascular space, as defined

376 previously.

377 Solving equations $10-11$ for an inversion recovery sequence gives the bi-exponential 378 solution:

$$
S=S_{0}\left[1-2\left(a_{S} e^{\frac{-T I}{T_{1, S}}}+\left(1-a_{s}\right) e^{\frac{-T I}{T_{1, L}}}\right)\right]
$$

379 where $S_{0}$ is the equilibrium signal, a product of water density and scanner calibration factors,

$380 \mathrm{Tl}$ is the inversion time, and $a_{s}$ is the apparent (measurable) volume fraction of the short $T_{1}$ 381 compartment given by: 


$$
a_{s}=\frac{1}{2}-\frac{1}{2}\left(\frac{\left[\left(\frac{1}{T_{1, e}}-\frac{1}{T_{1, b}}\right)\left(2 p_{b}-1\right)+\left(k_{\text {in }}+k_{\text {out }}\right)\right]}{\left[\left(\frac{1}{T_{1, e}}-\frac{1}{T_{1, b}}+k_{\text {out }}-k_{\text {in }}\right)^{2}+4 k_{\text {in }} k_{\text {out }}\right]^{\frac{1}{2}}}\right)
$$

384 The relaxation rates $1 / T_{1, \mathrm{~S}}$ and $1 / T_{1, \mathrm{~L}}$ are the apparent (observed) $T_{1}$ relaxation rates of each 385 compartment, and are given by:

$$
\begin{aligned}
\frac{1}{T_{1, S / L}}=\frac{1}{2}\left[\left(\frac{1}{T_{1, e}}+\frac{1}{T_{1, b}}+k_{\text {in }}+k_{\text {out }}\right)\right. \\
\left. \pm\left[\left(\frac{1}{T_{1, e}}-\frac{1}{T_{1, b}}+k_{\text {out }}-k_{\text {in }}\right)^{2}+4 k_{\text {in }} k_{\text {out }}\right]^{\frac{1}{2}}\right]
\end{aligned}
$$

386 Inversion recovery measurements of $T_{1}$ are time-consuming, which limits brain coverage.

387 Spoiled gradient echo acquisitions (SPGR) are faster enabling full brain coverage, but are

388 more sensitive to transmit $B_{1}$ field inhomogeneity. The two-site exchange model for the

389 SPGR sequence is given in [31].

390 Equations 10-11 are functions of time only, and assume that magnetisation is 'well mixed'

391 within each space. If the BBB is damaged and contrast agent extravasates into the

392 interstitial space, interstitial $T_{1}$ may decrease sufficiently to drive extravascular $T_{1}$ relaxation

393 into a bi-exponential regime (i.e. no longer a single well-mixed compartment). In this case,

394 models that take transcytolemmal water exchange into account may be required to

395 accurately describe the system [33,34]. In the vascular compartment, while the exchange of

396 water between plasma and red blood cells is extremely fast $\left(k \sim 40-80 \mathrm{~s}^{-1}\right)$, large contrast

397 agent concentrations that occur during first pass of a bolus injection may transiently tip

398 relaxation into a bi-exponential regime (for plasma contrast agent concentrations $>10 \mathrm{mM}, r_{1}$

$399=3.5-4.5\left(\mathrm{mM} \mathrm{s}^{-1}\right)$. Following first pass, the concentration in plasma is much lower $(\sim 1-2$

$400 \mathrm{mM}$ ) and blood water can be assumed to decay with a single $T_{1}$. 
401 Equations 10-11 describe the evolution of intravascular (capillary) and extravascular

402 magnetisation during each TR or inversion recovery period. In 3D SPGR acquisitions, inflow

403 and outflow of magnetisation into and from the capillary bed can be ignored, as by the time

404 of measurement (i.e. acquisition of the centre of k-space), steady state conditions will be

405 met, and inflowing magnetisation will equal that flowing out of the capillary bed. In multislice

406 2D acquisitions, inflow of partially saturated blood may mean that arterial magnetisation

407 exceeds outflow from the venous compartment. In this case, models should be adapted to

408 account for differences between the amount of magnetisation entering and leaving the

409 capillary bed [35].

\section{$410 \quad 5.2$ Exchange models for arterial spin-labelling based measurements}

411 Arterial spin labelling (ASL) forms the second major type of MRI acquisition currently used to

412 measure BBB water exchange. In ASL, a perfusion weighted label image is acquired and

413 subtracted from an identical image without label. A post-labelling delay (PLD) time is

414 introduced following the label pulse to allow labelled blood to reach the tissue of interest.

415 Original ASL models are based on the single compartment Kety model for freely diffusible

416 tracers $[36,37]$. They incorrectly assume that all labelled water immediately exchanges from

417 capillary to the extravascular space $\left(P S_{w} \rightarrow \infty\right)$. Conflicting views exists relating to the

418 importance of this effect in standard ASL acquisitions. Several studies have shown that

419 applying a single compartment model to ASL data can lead to errors of up to $62 \%$ in $C B F$

420 [38-40], particularly in white matter where $T_{1}$ differences between intra- and extravascular

421 spaces are substantial. Conversely, in rat brain at 9.4T, Carr et al. showed changes in signal

422 intensity caused by typical changes in $P S_{w}$ were too small to be detectable at the SNR

423 achievable using a standard FAIR sequence of the time [41].

424 Following these observations, a number of two-compartment models were proposed (Figure

425 4), and specialized ASL techniques developed to correct CBF estimates for finite $P S_{\mathrm{w}}$, or to

426 directly quantify the BBB water exchange rate itself. The following sections describe these 
two-compartment models and their assumptions; specialist ASL methods for quantifying

428 BBB exchange are discussed in later sections.

429 Models describing the rate of change of labelled magnetisation in capillary and extravascular

430 spaces were first described by Zhou et al [42] and Parkes et al. [38]:

$$
\frac{d}{d t} \Delta M_{b}(t)=\frac{-\Delta M_{b}(t)}{T_{1, b}}+\frac{f}{v_{b}} \cdot \Delta M_{a}(t)-\frac{f}{v_{b}} \cdot \Delta M_{v}(t)-k_{\text {in }} \Delta M_{b}(t)+k_{\text {out }} \Delta M_{e}(t)
$$

$$
\Delta M(t)=\Delta M_{b}(t)+\Delta M_{e}(t)
$$

where $\Delta M_{a}(t), \Delta M_{v}(t), \Delta M_{b}(t)$, and $\Delta M_{e}(t)$ are the magnetisation differences between label and control images for the arterial blood, venous blood, capillary blood, and extravascular space respectively, and $f$ is the flow feeding the capillary bed, where $[f]=(\mathrm{mL}$ blood $) \mathrm{min}^{-1}$ $(\mathrm{mL} \text { tissue })^{-1}$. It is worth noting that the exact form of equations 17-19 depend on how the magnetisation and physiological parameters are defined.

441 The solutions to Eqns 17-18 are known [38], but require knowledge of both $\Delta M_{a}$ and $\Delta M_{v}$. The arterial magnetisation $\Delta M_{a}$ is defined by the labelling pulse and is therefore approximately known and or can be accurately modelled. However, $\Delta M_{v}$ is typically unknown. Under conditions of infinitely fast exchange, then labels in the capillary and extravascular spaces are assumed to be in equilibrium, and label leaving the voxel will equal 446 that in the extravascular space, weighted by the tissue-blood partition coefficient: $\Delta M_{v}(t)=$

$447 \frac{\Delta M_{e}(t)}{\lambda}$. Under conditions of finite water exchange, $\Delta M_{v}$ and $\Delta M_{e}$ may not be in equilibrium by 448 the time of measurement, or by the time the labelled water begins to leave the tissue.

449 Parkes et al. suggest two possible options for modelling $\Delta M_{v}$ under conditions of finite exchange, termed slow and fast flow approximations [43]. In the slow flow approximation, 
451 which is valid for low perfusion rates (i.e., high extraction fraction, e.g. in human brain), the

452 proportion of label predicted to pass straight into the venous pool will be a small fraction of 453 the total detectable label $(1-E=0.1$, where $E$ is the extraction fraction). Furthermore, since 454 the measurement time (post-labelling delay time) will be less than the mean vascular transit 455 time, the label that remains intravascular may not have physically reached the venous pool 456 by the time of measurement. Overall therefore, under conditions of low flow, it is a good assumption that $\Delta M_{v} \cong 0$. In the fast flow approximation, at higher perfusion rates where 458 extraction of labelled water is lower and vascular transit times are shorter (e.g. in rodents, $E$ $459 \sim 0.7$ ), the proportion of label that remains intravascular and reaches the venous pool may 460 be a significant fraction of the total detectable label. In these circumstances, the transit time 461 of label through the blood compartment will be small and the venous label magnetisation can be approximated by that at the capillary outlet: $\Delta M_{v} \cong \Delta M_{b}$.

463 To simplify the two-compartment exchange model further, Parkes et al. and St Lawrence et

464 al. introduced a zero backflux assumption $\left(k_{\text {out }}=0\right)[40,44]$. This is justified since the extravascular compartment is much larger than the intravascular compartment. For example, assuming a $p_{\mathrm{b}}$ of 0.05 and $k_{\text {in }}$ of $3 \mathrm{~s}^{-1}, k_{\text {out }}=0.16 \mathrm{~s}^{-1}$. At long post-labelling delay times and

467 high $P S_{w}$, this assumption may be inaccurate, as most of the label will reside within the extravascular compartment, and efflux of label from the extravascular compartment may equal or be greater than influx, despite low $k_{\text {out. }}$ This zero backflux assumption was termed the single pass approximation (SPA), and has also been applied by St. Lawrence et al. to distributed models (see later)[45].

Alsop et al. [46] proposed an alternative two-compartment model for describing ASL signals, but did not explicitly describe its use for quantifying trans-BBB exchange at the time. This model used the existing architecture of the one-compartment Kety 'tissue' model [36,37], but added an 'adhoc' arterial and capillary compartment. By defining an arterial transit time $\left(\delta_{a}\right.$;

476 the transit time from the labelling position to the voxel), and tissue transit time ( $\delta$; the transit 477 time from the labelling position to the extravascular space), the two model components were 
478 linked by assuming that the BBB simply slows the delivery of label from the vasculature to

479 the blood. As in the original Kety model, all labelled water exchanges into the tissue, and is

480 simply delayed in getting there by a time: $T_{\mathrm{ex}}=\delta-\delta_{\mathrm{a}}$. Venous outflow is treated in the same

481 manner as the Kety model, assuming venous label is instantaneously equilibrated with the

482 extravascular label. This latter assumption requires infinitely fast water exchange,

483 contradicting the prior assumption of finite exchange time $T_{\text {ex. }}$. It is unclear how this will affect

484 accuracy of $T_{\text {ex }}$ estimates, but may be significant at high flow rates (i.e. in rodents).

485 Equations 17-18 describe the evolution of longitudinal magnetisation. However, ASL signal

486 is also weighted by transverse relaxation $\left(T_{2}\right)$, due to the moderate echo times used. Wells

487 et al. showed the $T_{2}$ of labelled water changes with post-labelling delay time [47], indicating

488 that the $T_{2}$ values of water in vascular and extravascular compartments differ, and could

489 impact the accuracy of water exchange measurements in methods that do not account for

490 compartmental $T_{2}$ differences. Based on these findings, Gregori et al. adapted the Alsop et

491 al. model [48] to account for differences in both $T_{1}$ and $T_{2}$.

492 The models of Zhou et al., Parkes et al., Gregori et al. and Alsop et al. described above

493 assume the label is well-mixed within both the capillary and extravascular spaces. In reality

494 labelled blood water is progressively extracted as it passes through the capillary bed. The

495 tissue homogeneity model first proposed by Johnson and Wilson models the label

496 concentration as a function of both time and position along the capillary bed, and the

497 extravascular space as function of time only (i.e., compartment assumption), but has no

498 closed form solution [49]. In 1998, St Lawrence et al. proposed an adiabatic approximation

499 to the homogeneity model, which provides a time-domain solution by assuming the rate of

500 change of label in the extravascular compartment is much slower than that in the vascular

501 compartment [50], which can be justified when considering the much larger relative volume

502 of the extravascular space.

503 A potential inaccuracy with many of the proposed models is that they assume that the

504 labelled water is available to exchange immediately as it reaches the tissue. This may not be 
506 it enters the capillary bed. To account for this additional delay, Li et al. added an additional

507 pre-capillary compartment with associated transit time $t_{e x}$ to a standard tissue homogeneity

508 model [51]. Applying the model to healthy human brain tissue, a mean delay time $t_{\mathrm{ex}}$ of 0.51

509 s seconds was observed, suggesting water does not begin to exchange immediately once it

510 has entered the voxel.

\begin{tabular}{|c|c|c|}
\hline $\mathrm{CBF}$ & Cerebral blood flow & $\mathrm{mL}$ (blood) $\mathrm{mL}$ (tissue) $)^{-1} \mathrm{~min}^{-1}$ \\
\hline$k_{\text {in }}$ & Exchange rate of water from blood to & $\min ^{-1}$ \\
\hline$k_{\text {out }}$ & Exchange rate of water from brain to & $\min ^{-1}$ \\
\hline$J$ & Unidirectional magnetisation flux & (magnetisation) $\min ^{-1}$ \\
\hline$P S_{w}$ & $\begin{array}{l}\text { Permeability surface-area product to } \\
\text { water }\end{array}$ & $\mathrm{mL}$ (blood or extravascular fluid) $\mathrm{mL}$ (tissue) $)^{-1} \mathrm{~min}^{-1}$ \\
\hline$E$ & Extraction fraction & Fraction of blood water extracted in a single pass \\
\hline$T_{\mathrm{b}}$ & Mean blood water residence time & s \\
\hline$T_{\text {ex }}$ & Pre-exchange lifetime $\left(=T_{\mathrm{b}}\right)$ & $\mathrm{s}$ \\
\hline$\delta$ & Tissue transit time & s \\
\hline$\delta_{a}$ & Arterial transit time & s \\
\hline$T_{\mathrm{e}}$ & Mean extravascular residence time & $\mathrm{s}$ \\
\hline$V_{\mathrm{b}}$ & Absolute blood volume & $\mathrm{mL}$ \\
\hline$V_{e}$ & Absolute extravascular volume & $\mathrm{mL}$ \\
\hline$V_{\mathrm{T}}$ & Absolute voxel volume & $\mathrm{mL}$ \\
\hline$v_{\mathrm{b}}$ & Fractional blood volume & $(\mathrm{mL}$ blood $)(\mathrm{mL} \text { tissue })^{-1}$ \\
\hline$v_{\mathrm{e}}$ & Fractional interstitial volume & $\left(\mathrm{mL}\right.$ extravascular space) $(\mathrm{mL} \text { tissue })^{-1}$ \\
\hline $\mathrm{p}_{\mathrm{b}}$ & Blood water population fraction & $\left(\mathrm{mL}\right.$ blood water) $(\mathrm{mL} \text { blood }+ \text { extravascular water })^{-1}$ \\
\hline $\mathrm{p}_{\mathrm{e}}$ & Extravascular water population & $(\mathrm{mL}$ extravascular water $)(\mathrm{mL} \text { blood }+ \text { extravascular water })^{-1}$ \\
\hline$\lambda$ & Brain-blood partition coefficient & Magnetic moment (mL tissue $)^{-1 /}$ magnetic moment $(\mathrm{mL} \text { blood })^{-1}$ \\
\hline$M_{\mathrm{t}}$ & Total voxel magnetisation & Magnetic moment per unit volume of tissue \\
\hline$M_{\mathrm{b}}$ & Blood magnetisation & Magnetic moment per unit volume of blood \\
\hline$M_{\mathrm{e}}$ & Extravascular magnetisation & Magnetic moment per unit volume of extravascular space \\
\hline $\mathrm{M}_{0, \mathrm{~b}}$ & Equilibrium blood magnetisation & Magnetic moment per unit volume of blood \\
\hline $\mathrm{M}_{0, \mathrm{e}}$ & $\begin{array}{l}\text { Equilibrium extravascular magnetisation } \\
\text { density }\end{array}$ & Magnetic moment per unit volume of extravascular space \\
\hline
\end{tabular}

511

512 6. MRI approaches for quantifying BBB water exchange

513 There are currently two main MRI approaches for measuring BBB water exchange, those

514 that use a contrast agent, and those that do not (contrast agent free). Contrast agent based

515 approaches utilize the relaxation effects of injectable paramagnetic contrast agents to

516 shorten the $T_{1}$ relaxation rate of water in blood relative to water in the extravascular space, 
517 pushing longitudinal relaxation of voxel water from a mono-exponential (in the limit of

518 infinitely fast exchange between compartments) to an exchange-dependent bi-exponential

519 regime. Contrast agent free approaches generally employ arterial spin labelling MRI (usually

520 in combination with $T_{2}$ - or diffusion-weighting) to track exchange of labelled water as it

521 passes from blood to brain. In either case, the critical challenge lies in precisely and

522 accurately distinguishing components of signal arising from intravascular and extravascular

523 water.

524 The following sections summarize methods proposed to date for measuring BBB water

525 exchange, and provide discussion of their main assumptions and limitations. Hybrid

526 approaches that combine contrast agents with ASL, in addition to a number of more recent

527 approaches, are also discussed. All methods are summarised in Table 3. 
1-comp Kety mode

(Kety et al. Williams et al. Buxton et al.)

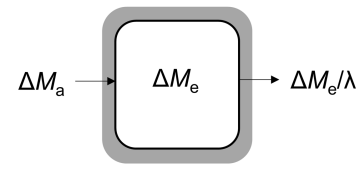

\section{Compartment models}

General two-compartment model

(Zhou et al.,Parkes et al., St-Lawrence et al.)

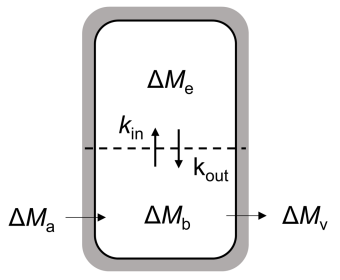

1-comp Kety + vascular compartment

(Alsop et al., Wells et al., Ohene et al., Gregori et al.)
Distributed models

Tissue homogeneity model (Wilson et al.)

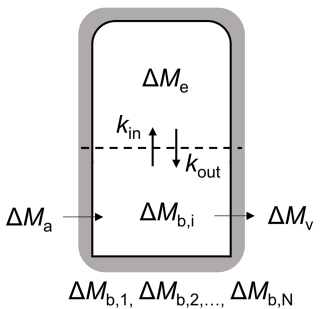

e Four-phase capillary stepwise model (Li et al.)

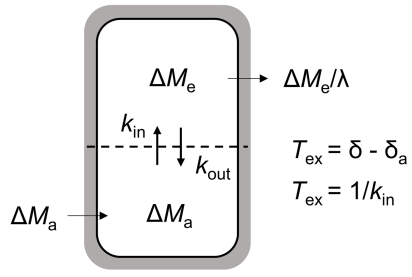

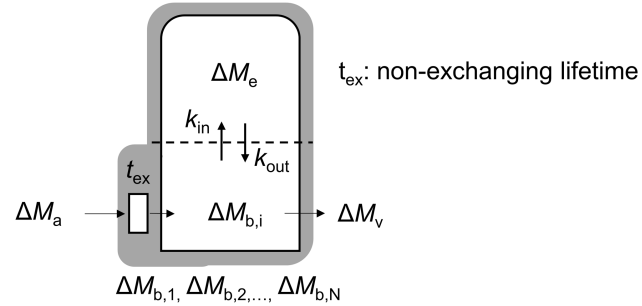

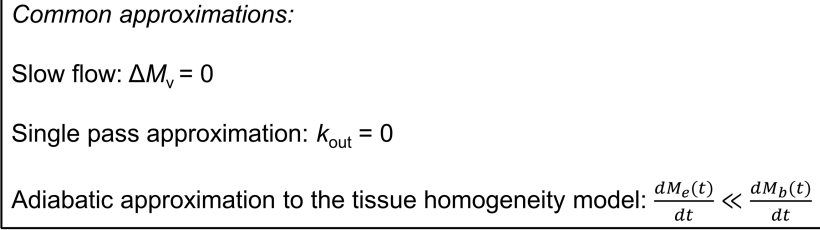

Figure 4. Kinetic models for measurement of BBB water exchange using ASL. a the standard Kety model used for most ASL CBF measurements. The lack of a vascular compartment leads to bias in CBF estimates when blood-tissue $T_{1}$ differences are large (i.e., in white matter), and when venous water has not equilibrated fully with tissue water (i.e., high flow). b The general two-compartment exchange model. Common approximations to this model include the slow flow approximation, which assumes that $\Delta M_{v}=0$, and the single pass approximation (SPA) which assumes that label does not have time to re-exchange back into the blood compartment before the measurement time. $\mathbf{c}$ The Kety model with an 'adhoc' vascular compartment. In contrast to the general two-compartment model, the input to the extravascular compartment is the same as the input to the vascular compartment (i.e., $\Delta M_{\mathrm{b}}=\Delta M_{\mathrm{a}}$ ). $\mathbf{d}$ The general tissue homogeneity model, in which the vascular space is modelled as a plug flow instead of a well-mixed compartment (distributed compartments designed by square edges). Common approximations with time domain solutions include the SPA and adiabatic approximation (AATH).e The four phase capillary stepwise model of Li et al. A non-exchanging compartment is included to account for transit through larger non-exchanging vessels. 
546 Contrast agent based approaches aim to modify the $T_{1}$ of blood water using an exogenous

547 intravascular contrast agent, such that the combined relaxation of the voxel (intra- and

548 extravascular spaces) relaxes in a manner dependent on the BBB water exchange. If the

549 sum, $k_{\text {in }}+k_{\text {out }}$, is much greater than the magnitude difference in intra- and extravascular

550 relaxation rates, then water will be able to sample both compartments before substantial

551 relaxation can occur, leading to mono-exponential 'exchange rate independent' $T_{1}$

552 relaxation. This condition is met under most 'non-contrast' conditions in both gray and white

553 matter. For example, in gray matter, the difference in relaxation rates between intra- and

554 extravascular spaces is of the order $\Delta R_{1}=\left|1 / T_{1 \mathrm{e}}-1 / T_{1 \mathrm{~b}}\right| \sim|1 / 1.5-1 / 1.7| \mathrm{s}^{-1} \sim 0.078 \mathrm{~s}^{-1}$ at $3 \mathrm{~T}$

$555[52,53]$, which is much smaller than the sum of typical BBB water exchange rates, $k_{\text {in }}+k_{\text {out }} \sim$

$5563 \mathrm{~s}^{-1}$ [28]. In white matter, the blood and tissue $T_{1}$ values are more different, yet $\Delta R_{1}$ remains

557 much smaller than $k_{\text {in }}+k_{\text {out, }}$, for example $\Delta R_{1} \sim|1 / 1.1-1 / 1.7| \mathrm{s}^{-1} \sim 0.32 \mathrm{~s}^{-1}[52]$.

558 In the presence of an intravascular contrast agent, blood water $T_{1}$ becomes shorter and 559 intravascular-extravascular relaxation rate differences become of the order of $k_{\text {in }}+k_{\text {out }}$ or

560 larger. For example, assuming a blood contrast agent concentration of $1 \mathrm{mM}$ (a typical post

561 contrast concentration during the washout period following a standard dose of gadolinium

562 contrast media in humans [54]) and contrast agent $T_{1}$ relaxivity $r_{1} \sim 4.5(\mathrm{~s} \mathrm{mM})^{-1}$,

563 intravascular-extravascular relaxation rate differences in gray matter are of the order $\Delta R_{1} \sim$

$564|1 / 1.5-1 / 0.20| \sim 4.3 \mathrm{~s}^{-1}$, which is greater than $k_{\text {in }}+k_{\text {out. }}$ Under these conditions $\left(\Delta R_{1}>k_{\text {in }}+\right.$

$565 k_{\text {out }}$ ), the system is in the intermediate/slow exchange regime, and the observed $T_{1}$ relaxation

566 of the voxel is bi-exponential and exchange-rate dependent. By acquiring MRI images in

567 both fast, and intermediate/slow exchange regimes, exchange rate information can be

568 distinguished from other factors affecting MRI signals, including intrinsic relaxation rates,

569 and water population fractions. The following sections describe approaches that utilize

570 contrast agents to modify blood $T_{1}$ in order to measure water exchange across the BBB. 
572 Schwarzbauer et al. measured BBB $P S_{w}$ in rats at $7 \mathrm{~T}$ using a stepped infusion technique

573 [26]. As the infusion rate was increased, $T_{1}$ values of tissue and blood were measured in a

574 single slice using a snapshot inversion-prepared spoiled gradient-recalled echo sequence

575 (IR-SPGR). Each time the infusion rate was increases, relaxation of blood and extravascular

576 water was pushed further towards the intermediate-slow exchange regime, resulting in a

577 series of tissue $T_{1}$ measurements with varied sensitivity to BBB water exchange. To maintain

578 constant blood concentrations for the duration of each $T_{1}$ measurement, a macromolecular

579 contrast agent expected to have minimal BBB leakage and renal excretion was used (Gd-

580 DTPA-polylysine, $75 \mathrm{kDa}$ ). The range of $\Delta R_{1}$ values obtained was $\sim 0.05-12 \mathrm{~s}^{-1}$ (as read

581 from Figure 5 in [26]).

582 A simplified two-compartment exchange model was used to describe the dependence of

583 tissue $T_{1}$ on $p_{\mathrm{b}}$ and $P S_{\mathrm{w}}\left(\right.$ Equations 10-11 with $\left.a_{\mathrm{S}}=0\right)$. Measurements of $P S_{\mathrm{w}}$ were made by

584 fitting Eqn 15 ( $T_{1, \mathrm{~L}}$ solution) to measured tissue $T_{1}$, essentially assuming the vascular

585 contribution to measured signals can be ignored. The validity of this assumption was tested

586 by taking the ratio of vascular to extravascular contributions to simple bi-exponential

587 relaxation, and found to be less than $3 \%$, even at the highest contrast agent concentration.

588 However, the authors' analysis neglected the effects of the SPGR readout on evolution of

589 magnetisation, and errors may be larger than stated.

590 Rooney et al. applied a similar approach to measure BBB $P S_{w}$ in subjects with glioblastoma

591 multiforme [28]. Instead of infusing the contrast agent, 3 injections of the superparamagentic

592 iron oxide nanoparticle (SPION) ferumoxytol were used to modify blood $T_{1}$. The use of

593 SPIONs in these cases was crucial to avoid any tissue $T_{1}$ effects caused by leakage of the

594 contrast across the BBB. $p_{\mathrm{b}}$ and $k_{\text {in }}$ were measured in a single slice using a similar IR-SPGR

595 sequence, model and assumptions to those of Schwarzbauer et al. By using fewer injections

596 and $T_{1}$ measurements, the total measurement duration was reduced to 40 minutes

597 compared to 2 hours for the Schwarzbauer et al. protocol. The range of blood-tissue $R_{1}$

598 differences were of a similar magnitude $\left(\Delta R_{1} \sim 0.04-14 \mathrm{~s}^{-1}\right.$ (as read from Figure 5 in [28]). 
599 Unfortunately, SPIONs are not widely approved use as diagnostic agents in humans, and

600 many candidate SPIONs have failed to gain regulatory approval, or have been withdrawn

601 from the market [55]. Intravascular gadolinium-based agents, such as gadofosvoset, may be

602 more translatable.

\section{$603 \quad 6.1 .2$ First pass methods}

604 First pass methods for measuring BBB water exchange were first proposed by Anderson et

605 al. with a focus on detecting subtle BBB abnormalities in Alzheimer's disease [27] and then 606 developed further by the same laboratory in 2015 [28]. The method uses a dynamic contrast

607 enhanced MRI acquisition to rapidly acquire $T_{1}$ weighted images before and after a bolus

608 injection of an intravascular $T_{1}$-shortening contrast agent. Both studies used gadoteriodol as

609 contrast agent. By measuring $T_{1}$ prior to the injection of the contrast agent, $T_{1}$ weighted

610 signals acquired during bolus passage were converted into quantitative $T_{1}$ values.

611 Because the method is applied as the contrast agent passes through the tissue for the first

612 time, the arterial blood contrast agent concentration has the potential to reach $\sim 5-10 \mathrm{mM}$ in

613 approximately 10-20 seconds, depending on injection speed, contrast agent dose, and

614 cerebral perfusion. The main advantage of this approach is therefore being able to sample a

615 wide range of water exchange conditions in a very short timeframe. In this study, the range

616 of blood and tissue $\Delta R_{1}$ values obtained during first pass was lower than in the dose

617 ramping studies discussed above $\left(\Delta \mathrm{R}_{1}=0.05-2.6 \mathrm{~s}^{-1}\right.$, as read from Figure 1 in [28]), but

618 the effect was sufficient to enable robust voxelwise estimation of $p_{\mathrm{b}}$ and $k_{\mathrm{in}}$. A relatively low

619 dose of gadoteriodol was injected relative to the typical doses given for low molecular weight

620 agents $(28 \mu \mathrm{mol} / \mathrm{kg}$ versus $100 \mu \mathrm{mol} / \mathrm{kg})$. Much larger effects, and more precise estimates

621 could be obtained by injecting larger doses. For example, in the case of intact BBB, a

622 standard dose of low molecular weight contrast media could be expected to produce

623 changes in $\Delta \mathrm{R}_{1}$ of between $0.05-23 \mathrm{~s}^{-1}$, based on a $T_{1}$ relaxivity of $4.5(\mathrm{mM} \mathrm{s})-1$ and

624 assuming a peak contrast agent concentration of $5 \mathrm{mM}$. 
625 However, because of the rapidly changing contrast agent concentrations, temporal

626 resolutions of approximately 1-2 seconds were required to capture the required information,

627 limiting coverage to a single slice. Modern acceleration methods such as compressed

628 sensing and multi-banding may enable full brain coverage, or an even higher sampling rate

629 during the bolus passage. Delay and dispersion of the bolus as it passes through the

630 capillary bed also means that capillary contrast agent concentrations are unlikely to be equal

631 to those at the arterial or venous measurement points, which may lead to errors in estimates

632 of $k_{\text {in }}$ and $P S_{\mathrm{w}}$.

\section{6.1.3 Water exchange index (WEI) method}

634 A number of studies have shown that BBB water exchange causes bias in steady-state

635 cerebral blood volume estimates made using pre- and post-contrast spoiled gradient echo

636 acquisitions [56-58]. In an attempt to minimize these biases, investigators have typically

637 used flip angles and repetition times that minimise the effect of water exchange on MRI

638 signals [56,59]. Based on this concept, Kim et al. develop a measure of BBB water

639 exchange based on quantifying the degree of bias in cerebral blood volume estimates

640 obtained when using flip angles that are sensitive to BBB water exchange, relative to flip

641 angles that are insensitive to water exchange $[29,58]$. This approach produces a water

642 exchange index (WEI) that is approximately linearly dependent on the water exchange rate

$643\left(k_{\text {in }}\right)$, and only minimally dependent on CBV. Advantages include simple acquisition

644 approach, full volume coverage, and no requirement for complicated modelling. Limitations

645 include a strong dependence of WEI on TR, meaning that sequence standardization is

646 required to ensure WEI values can be compared across studies. The approach also requires

647 an intravascular contrast agent with a long circulating half-life such that the concentration of

648 the agent in blood is the same for all post contrast images. Despite these limitations, this

649 approach has undergone the most validation. Several studies have shown alterations in WEI

650 in acute stroke models $[29,60]$ and further studies have demonstrated its sensitivity to BBB

651 changes caused by hypertonic mannitol and $\mathrm{CO}_{2}$ challenge in the mouse brain [30]. 
653 MFAME-MRI, proposed by the authors' group, adapts the approach of Kim et al. to obtain

654 quantitative estimates of $P S_{w}$ with full brain coverage [31]. The approach makes use of

655 clinically approved low molecular weight contrast agents, e.g. gadolinium-DTPA, or

656 gadolinium-DOTA, with the a priori assumption that it remains intravascular, or that the

657 leakage rate is low $\left(K^{\text {trans }}<10^{-3} \mathrm{~min}^{-1}\right)$.

$658 T_{1}$-weighted images are acquired as in a standard dynamic contrast enhanced MRI

659 acquisition. However, instead of maintaining a constant flip angle throughout, the post

660 contrast flip angle is varied, providing images with a range of $\tau_{\mathrm{b}}$ and $p_{\mathrm{b}}$ sensitivity. A long TR

661 is used to enable multiple gradient echoes to be acquired per TR for $T_{2}{ }^{*}$ decay correction. A

662 general two-site water exchange model (Eqns 10-11) is then fit to the decay-corrected multi-

663 flip angle signals to determine $P S_{w}$. Because the full 2-site exchange model is fitted, rather

664 than the simplified two-site model applied by Schwarzbauer et al. and Rooney et al, possible

665 errors caused by disregarding the vascular contribution are removed.

666 Due to the dependence of this approach on signals acquired at a range of different flip

667 angles, accurate measurement of $P S_{w}$ relies on homogeneous RF transmission (e.g.,

668 adiabatic excitation), or accurate measurement of a $B_{1}$ map. In addition, the two-site water

669 exchange model becomes inaccurate if significant leakage of contrast agent occurs. It was

670 shown that for low leakage rates, $T_{\mathrm{b}}$ and $p_{\mathrm{b}}$ are overestimated, but because $P S_{\mathrm{w}}$ is the ratio

671 of these two parameters, it is mostly unaffected. At larger leakage rates, estimates of $P S_{w}$

672 are likely to be biased, unless accumulation of contrast agent in the extravascular space via

673 BBB leakage is explicitly accounted for. This may, in principle, be achieved from the same

674 set of measurements, although practical implementation is an area of active research.

676 While models accounting for water exchange have been shown to improve accuracy of CBF measurements [38,51], individual estimates of water exchange rates derived from standard 
678 ASL data are imprecise [38,41]. This is due to the relatively small difference in blood and

679 tissue $T_{1}$ relaxation rates relative to the exchange rate, making it difficult to detect the

680 separate contributions of intravascular and extravascular label to the total ASL signal.

681 The following subsections describe a number of proposed methods that aim to improve the

682 ability to distinguish the proportions of labelled water in blood and tissue.

\subsubsection{Multi-TE ASL}

684

In 2009, Wells et al. showed that the multi-compartmental origin of labelled water could be determined using multi-echo ASL at $9.4 \mathrm{~T}$ [61]. The apparent $T_{2}$ of labelled water was found to increase with increasing post-labelling delay time, reflecting passage of water from a short $T_{2}$ compartment (blood) to higher $T_{2}$ compartment (tissue). Following on from this study, Wells et al. applied the same approach to quantify the BBB pre-exchange water lifetime ( $T_{\text {ex }}$, where $T_{\mathrm{ex}}=T_{\mathrm{b}}$ ) in mouse cortex, also at 9.4T [47]. Multi-echo subtraction signals were fitted with a bi-exponential $T_{2}$ decay model to extract intravascular and extravascular fractions as a function of post-labelling delay (PLD) time:

$$
\Delta M(P L D, T E)=\Delta M_{b}(P L D) e^{\frac{-T E}{T_{2, b}}}+\Delta M_{e}(P L D) e^{-\frac{-T E}{T_{2, e}}}
$$

693 To constrain fits, $T_{2}$ of the extravascular space (long $T_{2}$ ) was estimated first by fitting a

694 mono-exponential model to the control data (unlabelled data), then fixed in the bi-

695 exponential fit of Eqn 21 (with $T_{2, \text { control }}=T_{2, \mathrm{e}}$ ) to the subtraction data. Estimates of $\Delta M_{b}$ and

$696 \Delta M_{e}$ were then input into the adapted Kety model (Figure 4c) to estimate the pre-exchange

697 water lifetime. The mean cortical pre-exchange lifetime ( \pm s.e.m) averaged across mice was

$698370 \pm 42 \mathrm{~ms}$. Reliable estimation of pre-exchange lifetime in brain regions other than the cortex were not possible (e.g. hippocampus and striatum) due to poor precision of the biexponential fits, highlighting the challenge of achieving adequate signal to noise ratio using this approach. 
702 Gregori et al. applied a similar approach to estimate BBB water exchange in the human

703 brain [48]. A more complete model that jointly accounted for $T_{1}$ and $T_{2}$ decay was fitted,

704 assuming negligible backflow of label from tissue to blood and no venous outflow. This

705 model was based on the general kinetic model of Buxton et al. for pulsed ASL acquisitions,

706 yielding estimates of $T_{\mathrm{ex}}$ of $440 \mathrm{~ms}$.

707 In all these approaches, the pre-exchange lifetime $T_{\mathrm{ex}}$ is calculated by subtracting the arterial

708 transit time measured in a separate acquisition from the total tissue transit time (time from

709 labelling to exchange) as modelled by the adapted Kety model $\left(T_{\mathrm{ex}}=\delta-\delta_{\mathrm{a}}\right)$. The method

710 therefore relies on reliable estimation of arterial transit times, which may be problematic in

711 mice due to very high blood velocity. Optimised methods for measuring arterial transit times

712 in rodents should be used if possible [62]

713 The ability to quantify water exchange using multi-TE ASL depends entirely on intrinsic $R_{2}$

714 differences between intravascular and extravascular water (Table 2). As field strength

715 increases, the $R_{2}$ values of both blood and extravascular water increase; however, blood $R_{2}$

716 increases faster than extravascular $R_{2}$. Published data suggest that at $1.5 \mathrm{~T}, R_{2}$ of blood

717 water is lower than $R_{2}$ of extravascular water; however this relationship is reversed at or

718 above 3T for partially deoxygenated blood ( $80 \%$ oxygenated) and at or above $9.4 \mathrm{~T}$ for $100 \%$

719 oxygenated blood [47,52,63-67]. Differences between blood (80\% oxygenation) and tissue

$720 R_{2}$ are similar for field strengths between 1.5T and 7T, (approximately 3-6 s $\mathrm{s}^{-1}$ ), but increase

721 rapidly to approximately $40 \mathrm{~s}^{-1}$ at $9.4 \mathrm{~T}$ due to the much higher $R_{2}$ of blood water. 
Table 2. Blood and tissue $R_{2}$ variations with field strength. Blood $R_{2}$ values were taken from data with hematocrit in the range 0.4-0.45. References: a. Wansapura et al. [63], b. Stanisz et al. [52] c. Cox et al. [64], d. Krishnamurthy et al. [65], e. Zhao et al. [66], f. Silvennoinen et al. [67], g. Wells et al. [68]

\begin{tabular}{lllll}
\hline $\begin{array}{l}\text { Field } \\
\text { strength }\end{array}$ & $R_{2 \mathrm{~b}}\left(\mathrm{~s}^{-1} ; 100 \%\right.$ & $\mathrm{O}_{2 \mathrm{~b}}\left(\mathrm{~s}^{-1}, 80 \%\right.$ & $\begin{array}{l}R_{2 \mathrm{e}}\left(\mathrm{s}^{-1}, \text { gray }\right. \\
\text { matter })\end{array}$ & $\begin{array}{l}R_{2 \mathrm{e}}\left(\mathrm{s}^{-1}, \text { white }\right. \\
\text { matter })\end{array}$ \\
$1.5 \mathrm{~T}$ & $6.5^{\mathrm{f}}$ & $7.0^{\mathrm{f}}$ & $10.5^{\mathrm{b}}, 11.9^{\mathrm{c}}$ & $13.9^{\mathrm{b}}, 10.6^{\mathrm{c}}$ \\
$3 \mathrm{~T}$ & $8.8^{\mathrm{e}}$ & $18.3^{\mathrm{e}}$ & $12.5^{\mathrm{a}}, 10.1^{\mathrm{b}, 15.9^{\mathrm{c}}}$ & $9.1^{\mathrm{a}}, 14.5^{\mathrm{b}, 1} 13^{\mathrm{c}}$ \\
$7 \mathrm{~T}$ & $16.7^{\mathrm{c}}$ & $25^{\mathrm{c}}$ & $25.6^{\mathrm{c}}$ & $20^{\mathrm{c}}$ \\
$9.4 \mathrm{~T}$ & $30^{\mathrm{g}}$ & $66^{\mathrm{g}}$ & $26.3^{\mathrm{g}}$ & - \\
\hline
\end{tabular}

723 The strong dependence of $R_{2}$ on blood oxygenation level is likely to alter the precision of $T_{2^{-}}$

724 based water exchange measurements in an oxygenation-dependent manner (Table 2). At

$7259.4 \mathrm{~T}$, Wells et al. report that as the oxygenation of blood increases to near $100 \%$, precision

726 in estimates of $T_{\mathrm{ex}}$ is 'markedly lower than under air', because of the similarity of $T_{2, \mathrm{~b}}$ and $T_{2, \mathrm{e}}$

727 values under these conditions. Table 2 shows that at $7 \mathrm{~T}$, the opposite effect is expected,

728 with greater $R_{2}$ differences at $100 \%$ oxygenation than at $80 \%$ oxygenation. For preclinical

729 studies using $T_{2}$ to quantify BBB water exchange, the choice of anaesthetic carrier gas

730 should be carefully considered.

$731 \quad$ 6.2.2 Diffusion-weighted ASL

732 The pseudo-diffusion coefficient of vascular spins due to perfusion is approximately 10 times

733 that of extravascular spins [69]. By applying diffusion sensitising gradients of low strength,

734 vascular spins can be nulled, leaving only signal from spins in the extravascular

735 compartment. Therefore, by applying diffusion weighting following labelling in ASL

736 experiments, the proportion of label in each compartment can be determined as a function of

737 post labelling delay time.

738 Silva et al. first applied diffusion weighting to separate vascular and extravascular

739 contributions to ASL signal in rats [70]. Diffusion gradients were applied at 12 b-values along

740 a single direction immediately after a $3.5 \mathrm{~s}$ labelling pulse. Through applying an intra-voxel 
741 incoherent motion (IVIM) type model to the subtraction images, the authors were able to

742 estimate the fast (intravascular) and slow (tissue) diffusing fractions of the label and their

743 respective pseudo-diffusion /diffusion coefficients:

$$
\frac{\Delta M(t, b)}{\Delta M(t, b=0)}=A_{1}(t) e^{-b D^{*}}+A_{2}(t) e^{-b D}
$$

where $t$ is the PLD time and $A_{1}(t)+A_{2}(t)=1$. The amplitude of the extravascular fraction was found to decrease with hypercapnia, corroborating the expected decrease in the extraction fraction with increasing $\mathrm{CO}_{2}$ tension.

This basic approach was developed further by Wang et al. [71] by explicitly expressing the amplitudes of diffusion components $A_{1}$ and $A_{2}$ in terms of intravascular and extravascular label fractions:

$$
\begin{aligned}
& A_{1}(t)=\frac{\Delta M_{b}(t)}{\Delta M(t)} \\
& A_{2}(t)=\frac{\Delta M_{e}(t)}{\Delta M(t)}
\end{aligned}
$$

This description enabled measurements of $A_{1}$ and $A_{2}$ to be input into exchange models to estimate $k_{\text {in. }}$ By assuming values for the arterial transit time, $T_{1}$, and $T_{2}$, and by measuring the amplitudes $A_{1}$ and $A_{2}$ using multiple $\mathrm{b}$ value ( $7 \mathrm{~b}$-values, $0-300 \mathrm{~s} \mathrm{~mm}{ }^{-2}$ ) single delay time (PLD $=1.2 \mathrm{~s})$ ASL, Wang et al. were able to estimate $k_{\text {in }}$ using the SPA model. The PLD time was assumed to be longer than the arterial transit time, but shorter than the tissue transit time. In other words, it was assumed that the label was exchanging across the BBB at the measurement time.

Additional measurements of $A_{1}, A_{2}, D$ and $D^{\star}$ were made for a number of PLDs to demonstrate the signal behaviour as a function of delay time. The authors observed that as the delay time increased from $800-1500 \mathrm{~ms}$, the fraction of fast-diffusing label (assumed to be intravascular) diminished from approximately $39 \%$ to $15 \%$, consistent with exchange of label across the BBB. The diffusion coefficient of the fast diffusing compartment $\left(D^{*}\right)$ 
decreased from $0.34 \mathrm{~mm}^{2} \mathrm{~s}^{-1}$ at PLD $=800 \mathrm{~ms}$ to $0.069 \mathrm{~mm}^{2} \mathrm{~s}^{-1}$ at PLD $=1500 \mathrm{~ms}$, indicating

766 the presence of multiple flow regimes.

767 To speed up the data acquisition, the authors also presented a simplified method for

768 estimating $k_{\text {in }}$ using only two b-values $\left(0\right.$ and $50 \mathrm{~s} \mathrm{~mm}^{-2}$ ), and applied this approach to a

769 brain tumour patient (grade II, oligodendroglioma). They showed that a b-value of $50 \mathrm{~s} \mathrm{~mm}^{-2}$

770 spoils nearly all intravascular magnetisation (>98\%) but very little extravascular magnetisation $(<5 \%)$. Assuming that a bipolar gradient with $b=50 \mathrm{~s} \mathrm{~mm}^{-2}$ spoils all the intravascular magnetisation, the amplitudes can be approximated using the following expressions:

$$
A_{2}(t) \cong \frac{\Delta M(t, b=50)}{\Delta M(t, b=0)}
$$

$$
A_{1}(t) \cong 1-\frac{\Delta M(t, b=50)}{\Delta M(t, b=0)}
$$

776 This two-point approach elegantly removes the need to model intravascular flow

777 characteristics, which can vary as the label moves from arteriole to capillary (see above).

778 Since blood in arterioles has a velocity greater than in capillaries, all downstream label will

779 be nulled regardless of its pseudo-diffusion coefficient. The approach will fail to produce

780 accurate estimates if the PLD is shorter than the arterial transit time ( $k_{\text {in }}$ overestimated), or if

781 exchange has completed by the time of measurement (combination of short arterial transit

782 time and high $k_{\text {in }}$ ). Longer delay times will likely be beneficial for ensuring label is most

783 consistently within the capillary compartment across subjects, but this must be balanced

784 against the loss of label due to $T_{1}$ relaxation.

785 Since labelling occurs non-locally to the voxel of interest, estimation of $k_{\text {in }}$ requires

786 knowledge of the arterial transit time. The same is true for all ASL based measurements of

787 BBB water exchange. St. Lawrence et al. proposed estimating arterial transit time using a

788 DW-ASL acquisition with $b$ value of $10 \mathrm{~s} \mathrm{~mm}^{-2}$ at an intermediate PLD [72,73]. The b-value

789 of $10 \mathrm{~s} \mathrm{~mm}^{-2}$ was chosen to crush label in the arterial compartment, while leaving capillary 
and tissue label unaffected. By comparing images with and without arterial crushers it is possible to deduce when the label arrives at the tissue, if CBF is known or can be estimated.

792 The post-labelling delay time is set to be long enough such that the labelled blood has arrived in the imaging slice, but short enough such that exchange has not occurred (i.e. the label remains primarily in the arterial compartment).

Recently, Wengler et al. proposed a method for measuring BBB water permeability based on the intrinsic diffusion sensitivity of segmented gradient and spin echo (GRASE) readouts

797 [74]. In the image domain, pseudo-diffusion due to perfusion manifests as a point spread 798 function (PSF) that causes significant image blur. Meanwhile, the extravascular compartment experiences only negligible diffusion sensitivity along the echo train, resulting in different PSFs for the intravascular and extravascular spins. The difference image between label and control is given by:

$$
\Delta M=A_{1} \cdot \Delta M_{\text {true }} * P S F_{b}+A_{2} M_{\text {true }} * P S F_{e}
$$

where $\Delta M_{\text {true }}$ is the true difference image in the absence of point spread function effects, $A_{1}$ and $A_{2}$ are the relative amplitudes of the label in intravascular and extravascular spaces repsecitively, and $P S F_{b}$ and $P S F_{e}$ are the point spread functions of intravascular and extravascular label contributions due to pseudo-diffusion and diffusion respectively. The * operator denotes convolution. Data with different segmentation schemes were acquired at a PLD = $2000 \mathrm{~ms}$, varying the blurring effects of the vascular spins. The effect of the PSFs on the measured signal was estimated using augmented extended phase graphs, yielding

810 estimates of $A_{1}$ and $A_{2}$, which were then input into a version of Alsop's two-compartment

811 model [46], adapted to account for extraction fractions less than 1 . The authors assume that

812 exchange has completed by the time of imaging (PLD $\left.>\delta_{a}+T_{b}\right)$, and estimate $E$ and $f$

813 assuming that the exchange rate $k_{\text {in }}$ is known and fixed. The Renkin-Crone equation (Eqn 1)

814 is then used to estimate $P S_{\mathrm{w}}$ from $E$ and $f$. The former assumption may not be valid in cases 815 of high perfusion (i.e. in rodents). The latter assumption is odd since it imposes an unnecessary restriction that changes in $E$ are due to changes in vascular transit time, not 
817 changes in vessel permeability, $P$. Since vascular transit times are not measured, their

818 method can at best estimate $k_{\text {in }}$, not $P S_{w}$ as reported in the paper.

\section{6.2.3. Magnetisation transfer weighted ASL}

820 Silva et al. [75] proposed that intravascular and extravascular signals can be separated by

821 their different magnetisation transfer effects. ASL pairs were obtained with and without

822 saturation of macromolecules, and a two-compartment model used to describe exchange

823 between brain water and macromolecular spins. By knowing that macromolecular spins

824 interact more strongly with extravascular water, it was possible to deduce which

825 compartment the label was in at any given post-labelling delay time. Steady-state (i.e.

826 continuous labelling) measurements were obtained, and extraction fraction estimated.

\section{6.2.4 Contrast-enhanced ASL}

828 Estimating BBB water exchange from standard ASL data is challenging due to the similarity

829 of blood and tissue $T_{1}$ values. In essence it becomes impossible to know in which

830 compartment the label resides at the chosen delay time. The sections above describe

831 methods to distinguish label compartments using $T_{2}$-weighting, diffusion-weighting, or MT-

832 weighting. Another approach is to increase blood-tissue $T_{1}$ and/or $T_{2}{ }^{*}$ differences using

833 intravascular contrast agents.

834 Zaharchuk et al. proposed the continuous assessment of perfusion by tagging including

835 volume and water extraction (CAPTIVE) method in 1998 [76]. The method focused on

836 altering blood-tissue $T_{2}{ }^{*}$ differences, while minimizing effects on $T_{1}$. This was done because

837 a shorter blood $T_{1}$, usually the result of most paramagnetic contrast agents, would also

838 reduce the amount of label reaching the tissue, thus significantly reducing the SNR of post-

839 contrast images. To minimize $T_{1}$-shortening effects, a 'shift reagent' long circulating agent

840 (MPEGs-PL-DTPA) was used, which had a large effect on blood and tissue $T_{2}{ }^{*}$, but only a

841 small effect on blood $T_{1}$ and no effect on tissue $T_{1}$. This meant that label underwent similar

$842 T_{1}$ relaxation in both pre- and post-contrast datasets, but that $T_{2}{ }^{*}$ of blood and tissue was 
843 much shorter post-contrast. Crucially, label residing in the intravascular space was assumed

844 to be completely nulled in post-contrast images, leaving only label in tissue, albeit reduced

845 significantly due to $T_{2}{ }^{*}$ effects. Assuming $T_{1}$ effects were small, the ratios of pre- and post-

846 contrast subtraction images acquired at long pulse labelling delay times were equated to the

847 extraction fraction of labelled water. This approach is similar in concept to the DW-ASL

848 measurement proposed by Wang et al. [71], where a low b-value is used to null intravascular

849 label. The use of a contrast agent makes this approach more invasive, and is likely to have a

850 lower SNR since the contrast agent reduces $T_{2}{ }^{*}$ of tissue as well as that of blood.

851 A similar approach was proposed by the authors' group [77], but with several differences: i)

852 a clinical $T_{1}$ shortening contrast agent was used (1/4 dose), demonstrating that label is still

853 detectable, and highlighting the possibility for translation into humans, ii) multiple delay times

854 were used, enabling arterial transit time to be estimated simultaneously with the BBB water

855 exchange rate. $T_{2}{ }^{*}$ effects were smaller due to the use of a contrast agent with lower $r_{2}{ }^{*}$

856 relaxivity. The data suggested that a two-compartment model provided a substantially better

857 fit across all delay times than a purely vascular or purely extravascular model. Sensitivity to

858 water exchange increased as contrast agent dose increased from $0.8 \mathrm{~mL}$ to $2.1 \mathrm{~mL}$ of $\mathrm{Gd}$ -

859 DOTA, with estimates of $P S_{\mathrm{w}}$ decreasing from $67 \mathrm{~mL} \mathrm{~min} \mathrm{~mL}^{-1}$ to $1.5 \mathrm{~mL} \mathrm{~min}^{-1} \mathrm{~mL}^{-1}$ as

860 contrast agent dose was increased.

\section{$861 \quad$ 6.2.5 Phase-contrast ASL}

862 The water-extraction-with-phase-contrast-arterial-spin-tagging (WEPCAST) method takes a

863 unique approach to measuring $P S_{w}$ by quantifying the transmitted fraction of labelled water

864 passing into the superior sagittal sinus (SSS) during a single pass [78]. Models often

865 assume label reaching the venous compartment is small or negligible due to $T_{1}$ relaxation. In

866 this study, the authors show that when using multiple long delay times and pCASL, it is

867 possible to detect labelled water in the SSS, provided sufficient background suppression is

868 applied. 
869 Simulations performed in the study showed that the non-extracted fraction contributed

870 approximately $84 \%$ of the SSS signal, relative to label that re-exchanged back into the

871 bloodstream following leakage across the BBB. The SSS signal from subtraction images

872 was shown to increase with PLD time, reaching a maximum of $0.3-0.6 \%$ at approximately

$8732.5-3.5 \mathrm{~s}$, then decreasing to approximately $0.1-0.2 \%$ at $4.5 \mathrm{~s}$. The authors show a spatially

874 dependent signal enhancement throughout the SSS, reaching peak enhancement first in the

875 anterior SSS (at delay time of $2.5 \mathrm{~s}$ ), and last in the posterior SSS (at a delay time of $3.5 \mathrm{~s}$ ).

876 The authors then attempt to improve the detection sensitivity by including bi-polar phase-

877 contrast velocity-encoding gradients to better isolate signal arising from voxels containing

878 pure blood (i.e. the SSS), and remove that from voxels containing both blood and tissue (i.e.

879 voxels close to the SSS that would interfere via partial volume effects). In these datasets, a

880 quantitative model describing label contributions in the SSS is fitted to subtraction images to

881 estimate the global cerebral blood flow, and extraction fraction, from which whole-brain $P S_{\mathrm{w}}$

882 is estimated using the Renkin-Crone model.

883 Like the two-compartment ASL models applied to DW-ASL, the WEPCAST model requires

884 knowledge of blood and tissue $T_{1}$, which are fixed to literature values (but could in principle

885 be measured). Furthermore, the model accounts for temporal smoothing of the label as it

886 passes from the artery to SSS, likely improving model accuracy but adding additional

887 parameters to estimate alongside $\mathrm{E}$ and cerebral blood flow. Unfortunately, because the

888 method relies on measuring label in a large draining vein, it can only estimate global BBB

889 permeability, with no regional information. Combining WEPCAST with vessel-encoding

890 arterial tagging [79] may enable regional information on BBB permeability to be determined.

\section{$891 \quad 6.3$ Approaches based on injection of MRI-detectable water tracers}

892 Approaches described so far measure the trans-BBB exchange of endogenous water.

893 Another class of methods, similar in design to ${ }^{15} \mathrm{O}$-labelled water PET, aims to detect trans-

894 BBB exchange of injected water, enriched with either ${ }^{2} \mathrm{H}$ (deuterium) [80-82] or ${ }^{17} \mathrm{O}$ [83-91].

895 Such isotopes can be detected directly using multinuclear probes [80] or indirectly via their 
896 effect on ${ }^{1} \mathrm{H}$ relaxation [87] or, in the case of deuterium, effects on proton density. This

897 review will not discuss direct measurement and focusses mainly on indirect measurement

898 techniques, due to their greater translational potential.

$899 \quad 6.3 .1$ Indirect detection of ${ }^{17} \mathrm{O}$-labeled water via its effect on ${ }^{1} \mathrm{H} \mathrm{T}_{2}$

$900{ }^{17} \mathrm{O}-$ labelled water alters the $T_{2}$ of ${ }^{1} \mathrm{H}$ protons via scalar coupling of ${ }^{17} \mathrm{O}-{ }^{1} \mathrm{H}$. Detection of ${ }^{17} \mathrm{O}-$

901 labelled water using spin-echo based echo planar imaging (EPI) [90], $T_{2}$-weighted rapid

902 imaging with refocussed echo imaging (RARE) $[84,85,91]$, and steady state free precession

903 sequences $[86,92]$ have been proposed, enabling uptake and washout of ${ }^{17} \mathrm{O}$-labelled water

904 from the brain to be tracked with high temporal resolution ( $<10 \mathrm{~s}$ ). Ronen et al. proposed a

905 simplified 2-point method by acquiring post-injection spin-echo images with and without

906 sensitization to ${ }^{17} \mathrm{O}-{ }^{1} \mathrm{H}$ scalar-coupling [87]. This was achieved by collecting image sets with

907 and without RF irradiation applied during the readout.

908 Two studies performed quantitative analyses of ${ }^{17} \mathrm{O}$-labelled water enhancement curves.

909 Igarashi et al. [84] and Huber et al. [85] observed very rapid uptake of labelled water into

910 tissue and CSF spaces, followed by an equilibration phase that plateaued $300 \mathrm{~s}$ after

911 injection. To describe the curve shape of the equilibration phase, the investigators fitted an

912 empirical exponential decay model, $I=I_{0}+a^{*} \exp \left(-b^{*} \mathrm{t}\right)[84,85,91]$, with $I_{0}$ describing the

913 steady state attenuation, and $a$ the peak attenuation, and $b$ the washout rate. Unfortunately,

914 it was not clear from this study to what degree these parameters reflect BBB water

915 exchange. In a similar study, Kudo et al. [86] estimated ${ }^{17}$ O-labelled water concentration in

916 tissue and cerebrospinal fluid by comparing signals to calibration phantoms, providing the

917 possibility for quantitative kinetic analyses, and estimation of $k_{\text {in }}$ or $P S_{\mathrm{w}}$. These approaches

918 provide dynamic kinetic information at high temporal resolution and SNR. The main

919 disadvantage of the approach is the high cost of ${ }^{17} \mathrm{O}$-labelled water. 
921 Early attempts to detect ${ }^{2} \mathrm{H}$-labelled water were mainly by direct detection using ${ }^{2} \mathrm{H}$ receiver

922 coils $[80,82]$. Indirect detection methods were not pursued until recently [81], possibly

923 because of early evidence suggesting deuterium does not produce large effects on $T_{1}$ [93].

924 Wang et al. [81] presented a novel approach whereby ${ }^{2} \mathrm{H}$-labelled water was detected by its

925 proton replacement effect using EPI and RARE sequences. Since protons in ${ }^{2} \mathrm{H}$-labelled

926 water are invisible to ${ }^{1} \mathrm{H}$ MRI, as it perfuses and exchanges with tissue, the detectable ${ }^{1} \mathrm{H}$

927 signal reduces. Interestingly, ${ }^{2} \mathrm{H}$-labelled water was also found to have negative relaxivity,

928 increasing $T_{1}$ and $T_{2}$ of ${ }^{1} \mathrm{H}$ as its concentration increased. While potentially extremely useful

929 to study BBB dysfunction in rodents, this approach may not translate well to humans as

930 deuterium is toxic in large doses.

\section{7. Summary of published results}

9327.1 Water exchange across the BBB in healthy brain tissue

933 Measurements of BBB water exchange in healthy brain tissue are summarized in Tables 3

934 and 4 . Table 3 presents the actual measurements, and where missing, estimated values of

$935 k_{\text {in }}$ or $P S_{\mathrm{w}}$ assuming literature values for $v_{\mathrm{b}}$. Table 4 presents the mean and standard error

936 on the mean for $k_{\text {in }}$ and $P S_{w}$ in healthy human gray and white matter, and rodent gray matter

937 averaged across studies presented in Table 3. T-tests were performed to test the null

938 hypotheses of no difference in human gray and white matter water exchange parameters

939 (using measurements from studies where both gray and white matter water exchange were

940 measured in the same individuals), and no difference between human and rodent gray

941 matter water exchange parameters. $k_{\text {in }}$ was found not to differ significantly between healthy

942 human gray and white matter ( $p=0.55$, paired t-test), whereas $P S_{w}$ was significantly lower

943 in white matter $\left(p=0.0062\right.$, paired t-test), primarily because of the lower blood volume. $k_{\text {in }}$

944 and $P S_{w}$ did not vary between human and rodent gray matter $(p=0.62$ and $p=0.98$

945 respectively, unpaired t-tests).

9467.2 Water exchange across the BBB in disease 
947 Trans-BBB water exchange has been evaluated across a range of diseases including stroke,

948 obstructive sleep apnea (OSA), Alzheimer's disease (AD), small vessel disease, multiple

949 sclerosis (MS) and tumours. Results are summarised in Table 5 and discussed in detail in

950 the following sections.

\subsubsection{Water exchange across the BBB in stroke}

952 Kim et al. measured the water exchange index (WEI) to quantify changes in BBB water

953 exchange in the acute stages following permanent middle cerebral artery occlusion (MCAo)

954 in mice [29]. In the ipsilesional cortex, WEI was increased relative to contralateral brain

955 tissue, indicating increased BBB permeability to water. Huang et al. evaluated WEI 1 hour

956 following ischemic stroke and reperfusion [60]. WEI was found to be elevated in the

957 ipsilateral cortex, and more severely altered in animals with lower ipsilateral CBV. The

958 authors posited that the increase in WEI in animals with poor reperfusion (i.e. as quantified

959 by CBV) reflected higher levels of BBB damage and increased water permeability.

960 Tiwari et al. used DW-ASL to measure water exchange in a mouse model of transient MCAo

96190 minutes post stroke, then at 2 days post reperfusion [94]. At 90 minutes post occlusion,

962 no changes in $k_{\text {in }}$ or the fraction of vascular label fraction were observed. Following

963 reperfusion, significant reductions in $k_{\text {in }}$ and increases in the vascular label fraction were

964 observed. The authors suggest that changes in these parameters were caused by increased

965 BBB permeability to water; however, this interpretation is incorrect, as $k_{\text {in }}$ is proportional to,

966 not inversely proportional to, BBB permeability. The authors show large increases in CBF in

967 lesioned tissue, possibly caused by a chronic vasodilatory response to hypoxia. Increases in

968 vessel radius resulting from this could reduce $k_{\text {in }}$, in the absence of any changes in vessel

969 permeability.

971 The authors' group applied MFAME-MRI in a transgenic rat model of Alzheimer's disease

972 [31]. $P S_{w}$ was found to be higher in $A D$ rats relative to wild-types in several brain regions. 
973 Using $T_{2}$-weighted imaging of ${ }^{17} \mathrm{O}$-labelled water, Igarashi et al. found no difference in the

974 steady-state level of $\mathrm{H}_{2}{ }^{17} \mathrm{O}$ in a mouse model of $\mathrm{AD}$ [84], but CSF uptake was increased.

975 Shao et al. used DW-ASL to measure $k_{\text {in }}$ in patients at risk of small vessel disease [95]. $k_{\text {in }}$

976 was found to be significantly higher in persons with diabetes and hypercholesteriemia. $k_{\text {in }}$

977 correlated with white matter hyper-intensity severity, and was inversely correlated with

978 episodic memory scores from a picture sequence memory test.

\subsubsection{Water exchange across the BBB in obstructive sleep apnea}

980 Palomares et al. assessed BBB water exchange rate in patients with OSA using DW-ASL

981 [96]. Reductions in $k_{\text {in }}$ were observed in OSA patients relative to controls. No changes in

982 arterial transit time or cerebral blood flow were found. While no specific validation was

983 performed, it was suggested that since OSA is accompanied by hypoxia and cerebral

984 ischemia, reduced $k_{\text {in }}$ could result from hypoxia-induced reductions in aquaporin- 4 channels

985 at the BBB.

987 Rooney et al. compared $k_{\text {in }}$ between controls and subjects with relapsing remitting MS [28].

$988 k_{\text {in }}$ was reduced in normal-appearing GM $\left(k_{\text {in }}=120 \mathrm{~min}^{-1}\right.$ vs $\left.174 \mathrm{~min}^{-1}\right)$, normal-appearing

$989 \mathrm{WM}\left(k_{\text {in }}=132 \mathrm{~min}^{-1}\right.$ vs $\left.186 \mathrm{~min}^{-1}\right)$, and lesion regions $\left(k_{\text {in }}=108 \mathrm{~min}^{-1}\right)$ relative to controls. In

990 the same study, the authors hypothesized that changes to BBB $k_{\text {in }}$ are driven by the

991 metabolic activity of neurons via a chain of active transmembrane water cycling processes

992 resulting from neuronal $\mathrm{Na}^{+}-\mathrm{K}^{+}-\mathrm{ATP}$ ase activity. The contribution of ion pumps towards

993 transcytolemmal water exchange is well established [97-99]; however the link between BBB

994 water exchange and pump activity is not.

\subsubsection{Water exchange across the BBB in brain tumours}

996 Wang et al. found increased $k_{\text {in }}$ compared to normal tissue in a single patient with grade II

997 oligodendroglioma [71]. Conversely, Rooney et al. observed decreased $k_{\text {in }}$ in 5 patients with 998 glioblastoma multiforme [28]. These patients had prior surgical biopsy or resections followed 
999 by chemo-radiation therapy. While decreased water $k_{\text {in }}$ in these brain tumours is not

1000 implausible, it is counter-intuitive, since these tumours were also found to enhance on

1001 gadolinium-enhanced MRI, and yet the contrast agent is a much larger molecule than water.

1002 It was suggested that reduced $k_{\text {in }}$ in these tumours was caused by reduced sodium pump

1003 activity; however no validatory evidence was provided to support this claim.

1004 7.3. Water exchange across the BBB in knockout models

1005 Using multi-TE ASL, Ohene et al. observed an increase in the pre-exchange lifetime of water 1006 in cortex of aquaporin-4 deficient mice $\left(T_{\mathrm{ex}}=452 \pm 90 \mathrm{~ms}\right)$ relative to wild-types $\left(T_{\mathrm{ex}}=343 \pm\right.$

$100791 \mathrm{~ms}$ ), indicating a slower water exchange rate due to lower $P S_{\mathrm{w}}$ or higher $p_{\mathrm{b}}[100]$.

1008 Measuring uptake of $\mathrm{H}_{2}{ }^{17} \mathrm{O}$ tracer using $T_{2}$-weighted MRI, Igarashi et al. observed that the

1009 steady state level of $\mathrm{H}_{2}{ }^{17} \mathrm{O}$ in the cortex of rats was unaffected by both aquaporin-4 and 1010 aquaporin-1 deletion [101].

1011 Atochin et al. used the WEI approach to quantify trans-BBB water exchange in eNOS 1012 deficient mice [102]. eNOS is key signal transduction enzyme responsible for endothelium-

1013 dependent vasodilation, and cerebral blood flow. In knock-out mice, WEI significantly 1014 increased relative to wild-types.

10157.4 Technical validation of BBB water exchange measurements in rodents

1016 Several attempts to validate MRI-based BBB water exchange measurements have been 1017 made. Results are summarized in Table 6. The following section outlines the key results 1018 from these studies.

1019 Hypertonic mannitol has been used to alter BBB physiology in a number of studies $[30,75]$.

1020 Mannitol does not cross the BBB, and produces an osmotic gradient between the blood and 1021 extravascular space, pulling water into the bloodstream, and shrinking endothelial cells. This 1022 increases cerebral blood volume, and widens inter-endothelial tight junctions to 1023 approximately $200 \AA$, increasing BBB permeability [103]. Silva et al. showed, using 1024 magnetisation-transfer ASL, that mannitol increased water extraction fraction, indicating 
1025 increased $P S_{w}[75]$. Using the WEI method, Huang et al. observed increases in WEI and

1026 CBV as early as 15 minutes following mannitol injection [30].

1027 The effects of hypercapnia on BBB water exchange have also been studied. Hypercapnia 1028 causes vasodilation of capillaries and arterioles [104], increasing CBV and CBF. Increased 1029 leakage of injected tracers has been observed [105,106]; thus increases in water exchange 1030 would be expected either through an increased exchange area or increased number of open 1031 tight junctions. Using the WEI method, Huang et al. observed increases in WEI with $\mathrm{pCO}_{2}$ 1032 concentration [30]. Using DW-ASL, Silva et al. observed a reduction in the fraction of label 1033 remaining intravascular with hypercapnia, pointing towards increased $k_{\text {in }}$ [70]. However, 1034 since hypercapnia reduces arterial transit time, the label will have had more time to 1035 exchange before it was measured. Zahaurchuk et al. measured $P S_{w}$ with the CAPTIVE 1036 method, and found no change with increasing arterial $\mathrm{pCO}_{2}$ concentration [76]. Overall, the 1037 effects of mannitol on BBB water permeability appear to be more robust than those of $\mathrm{CO}_{2}$ 1038 challenge.

1039 Others investigators compared water exchange measurements to established permeability 1040 assays such as dynamic contrast enhanced MRI and Evans blue staining. In a model of 1041 middle cerebral artery occlusion (MCAo), Tiwari et al. showed decreased $k_{\text {in }}$ in the lesioned 1042 area following reperfusion [94]. The same animals were subject to dynamic contrast1043 enhanced MRI to measure the leakage rate of gadolinium-based contrast agent $\left(K^{\text {trans }}\right)$ in1044 vivo and Evans blue perfusion to visualize BBB integrity ex-vivo. Both measurements 1045 confirmed the spatial distribution of DW-ASL changes, but showed increased leakage, not 1046 decreased leakage as predicted by their $k_{\text {in }}$ measurements. These results support the 1047 potential for reduced BBB water permeability even in the presence of tight junction 1048 disruption, as reported by Rooney et al. in glioblastoma [28].

1049 The authors' group compared MFAME-MRI measurements of $P S_{w}$ to the expression of BBB 1050 proteins occludin, claudin-5, and aquaporin-4 in the TgF344-AD rat model of $A D$, and also 1051 cross-validated against gadolinium-DOTA leakage, measured using dynamic contrast- 
1052 enhanced MRI [31]. Occludin was expressed less in AD rats relative to controls, and

1053 correlated inversely with $P S_{w}$. Gadolinium leakage was not affected. This work indicates that

1054 measurements of water permeability are more sensitive to subtle tight junction changes of

1055 the type occurring in AD than measurements of gadolinium-DOTA leakage. .

1056 Using an aquaporin-4 facilitator drug and $T_{2}$-weighted imaging of $\mathrm{H}_{2}{ }^{17} \mathrm{O}$, Huber et al. showed 1057 steady-state signal loss $\left(I_{0}\right)$ in the cortex was reduced relative to placebo, indicating an 1058 increased BBB turnover of $\mathrm{H}_{2}{ }^{17} \mathrm{O}$ [85]. However, this measurement likely depends on $\mathrm{CBF}$, 1059 as well as blood and extravascular volume fractions, which may have also changed.

\subsection{Precision of water exchange measurements}

1061 The reliability and repeatability of water exchange measurements varies between methods, and depends fundamentally on the SNR of the data relative to the magnitude of water exchange effects. A precise BBB water exchange measurement should be capable of

1064 robustly separating intravascular and extravascular signal contributions in the presence of

1065 image noise. Factors including MRI coil sensitivity profile, readout bandwidth, voxel size, and 1066 the number of signal averages will also affect measurement precision.

1067

1068 Standard ASL provides low sensitivity to water exchange, with estimation of $k_{\text {in }}$ often failing 1069 entirely in both gray and white matter. In 2007, Carr et al. noted that to measure $P S_{w}$ with 1070 even a $100 \%$ coefficient of variation would require an SNR increase of approximately 2 1071 orders of magnitude, based on a typical ASL acquisition of the time [41]. Rodent studies 1072 using multi-TE ASL $[47,100]$ failed to provide reliable estimates outside the cortex, while the 1073 human multi-TE ASL produced reliable estimates only in gray matter regions [48]. Contrast agent based approaches were able to estimate $k_{\text {in }}$ in multiple cortical and subcortical gray matter regions [26,31]. First pass contrast agent methods and diffusion-weighted ASL

1076 approaches are the only methods to date that have demonstrated sufficient SNR to enable 1077 reasonable voxel-wise estimates across gray and white matter in the human brain $[28,72,95]$. 
1080 Several studies have formally measured scan-rescan reproducibility. Using DW-ASL with a

1081 2D readout, St Lawrence et al. measured scan-rescan reproducibility (intra-subject

1082 coefficient of variation) of $k_{\text {in }}$ to be $26 \%$ and $21 \%$ for gray and white matter regions respectively [72]. Using a DW-MRI with a 3D readout, Shao et al. obtained intra-subject correlation values of $0.52-0.72$ in cortical regions, 0.30 in the hippocampus, $0.57-0.74$ in the cingulum, and 0.63 in the precuneus [95]. Unpublished data from the author's group show that scan-rescan coefficient of variation for regional $P S_{w}$ estimates obtained using MFAMEMRI is approximately $40 \%$. No data currently exist on the scan-rescan reproducibility of first pass contrast-enhanced methods, or of multi-TE ASL.

1089

\section{Validity of a two-site model for BBB water exchange}

Models used to estimate BBB water exchange typically assume that intravascular and extravascular compartments are well-mixed. This section discusses the validity of this assumption.

In the intravascular space, water exchange rates across the red-blood cell membrane (intracellular to plasma) are of the order of $50-100 \mathrm{~s}^{-1}$ [107]. Using Eqn 8, and assuming a haematocrit of $42 \%$, the water exchange rate from plasma to the intracellular space is approximately $36-72 \mathrm{~s}^{-1}$, giving an average exchange rate of 43-86 s-1.

1100 In the extravascular space, the water exchange rate from the intracellular to interstitial 1101 compartment is of the order 1.4-2 $\mathrm{s}^{-1}$ [108], depending on cell type. Assuming brain cells in 1102 gray matter (neurones and glia) occupy approximately $80 \%$ of the extravascular volume 1103 (assuming $\sim 20 \%$ is taken up by interstitial volume [109]), the exchange rate from the 1104 interstitial compartment to the intracellular compartment is of the order of $5.6-8 \mathrm{~s}^{-1}$. The average exchange rate across the cellular membrane is therefore approximately $4.2-5 \mathrm{~s}^{-1}$. 
1106 This exchange rate is much lower than that across red-blood cells, primarily because of the

1107 larger size of brain cells.

1108

1109 The water exchange rate across the BBB from intra- to extravascular space $\left(k_{\text {in }}\right)$ is

1110 approximately $2.5 \mathrm{~s}^{-1}$ (taken from Table 4, calculated by taking the mean value across

1111 human gray and white matter, and rodent brain $\left.=151 \mathrm{~min}^{-1}\right)$. Assuming a blood volume of

$11125 \%$, the exchange rate from the extravascular space to the intravascular space is

1113 approximately $0.16 \mathrm{~s}^{-1}$, giving an average exchange rate across the BBB of $1.3 \mathrm{~s}^{-1}$.

1114

1115 Water exchange across the BBB is therefore approximately 40 times slower than that across

1116 red-blood cells, and approximately 3.5 times slower than that across brain cell membranes.

1117 It appears therefore that a two-compartment model may be a good assumption. However,

1118 while faster than BBB exchange, exchange between intravascular and extravascular sub-

1119 compartments may still not be sufficient to average together their relaxation and diffusion

1120 properties. Experimental evidence suggests that bi-exponential $T_{2}$ relaxation $[24,25,107]$ and

1121 diffusion occurs [110] in the intravascular space, and that extravascular diffusion is multi-

1122 compartmental [111]. Further work is needed to determine whether the limitations of water

1123 exchange across the BBB are sufficient to dominate relaxation or diffusion effects over those

1124 occurring within intra and extravascular compartments, or whether by ignoring these

1125 contributions, estimates of $k_{\text {in }}$ and $P S_{w}$ become biased.

1127 9. Physiological specificity of BBB water exchange measurements

1128 Contrast agent approaches provide greater physiological specificity than ASL-based

1129 approaches, as they are able to directly measure both $k_{\text {in }}$ and $P S_{w}$. From a biological point of

1130 view, it is not yet clear which parameter is likely to be most sensitive to pathology. Both $k_{\text {in }}$

1131 and $P S_{\mathrm{w}}$ depend linearly on vessel permeability. They both also depend on vessel radius

$1132(R)$, but in different ways. $k_{\text {in }}$ is inversely proportional to $R$, whereas the change in $P S_{\mathrm{w}}$ due

1133 to changes in $R$, depends on whether the vessel surface area remains constant (i.e. 
1134 increased vessel radius, but reduced vessel density) or changes (i.e. vasodilation at

1135 constant vessel density). The dependence of $k_{\text {in }}$ and $P S_{w}$ on vessel radius could be exploited

1136 to isolate $P$ via combined measurement of BBB water exchange and vessel size.

1137

\section{10. Conclusions}

1139 Studies undertaken so far report a wide range of $k_{\text {in }}$ and $P S_{w}$ values. These values are

1140 higher than for radioisotope methods by a factor of approximately 3-6. The reasons for this

1141 bias are currently unclear and require further study, with the current generation of MR-PET

1142 hybrid scanners providing an excellent opportunity for real-time direct comparison. Some

1143 methods appear to have superior sensitivity, but scan-rescan reproducibility data for all

1144 methods is lacking, making a valid comparison difficult. In rodents, where high doses of

1145 contrast agents can be used, contrast agent based approaches provide robust estimates of

1146 regional BBB water exchange. The two-point DW-ASL method of Wang et al. [71] has been

1147 applied the most frequently in clinical studies, and appears to provide robust estimates of $k_{\text {in }}$

1148 in human gray and white matter, as well as being entirely non-invasive. All ASL-based

1149 measurements of BBB water exchange depend on being able to accurately estimate arterial

1150 transit time. Care should be taken as biases in arterial transit time will propagate through to

1151 create bias in $k_{\text {in. }}$

1152 Literature summarised in this review shows BBB water exchange is altered in a wide range

1153 of diseases, including stroke, Alzheimer's disease, small vessel disease, diabetes,

1154 obstructive sleep apnea, multiple sclerosis, and cancer. In some applications, BBB water

1155 exchange rate increases (stroke, $A D$, smallvessel disease), indicating increased $B B B$

1156 permeability to water. In others (e.g. glioblastoma, obstructive sleep apnea), water exchange

1157 is reduced, indicating reduced water permeability, although apparently contradictory results

1158 cloud this picture. Further work is needed to understand the factors that contribute towards

1159 increased and decreased BBB water exchange in these conditions. 
1160 While a number of putative water transport routes are known, the physiological role of

1161 equilibrium BBB water exchange, and the contribution of each different transport pathway to

1162 normal and pathological brain functioning are poorly understood. This compares starkly with

1163 osmotically obliged water transport (non-equilibrium water exchange), which has been

1164 extensively studied due to its acute impact on health in stroke and traumatic brain injury

1165 [112]. There are currently many unresolved questions relating to equilibrium water

1166 exchange. Does equilibrium water exchange serve any physiological purpose (e.g.

1167 clearance of waste products, cell hydration), or is it a physical phenomenon with little

1168 biological impact? Does altered water transport indicate abnormalities in other potentially

1169 harmful processes (e.g. altered amyloid- $\beta$ clearance)? What is the principal route through

1170 which water travels across the BBB? What effect does increased or decreased equilibrium

1171 water exchange have on brain function? To what degree do physical barriers such as

1172 pericytes, basement membranes, and astrocyte end-feet limit entry of water into the brain?

1173 Is there a preferential destination for water upon entry into the brain (i.e. path of least

1174 resistance)? Do passive and active water transport processes impact on or interact with one

1175 another? These questions should be investigated in future BBB water exchange studies.

1176 While there are currently many excellent approaches for measuring water exchange using

$1177 \mathrm{MRI}$, there are also many opportunities to further improve these measurements.

1178 Simultaneously measuring the effect of BBB water exchange on multiple MRI contrasts (e.g.

$\left.1179 T_{1}, T_{2}, D\right)$, and jointly modelling these effects may increase precision and accuracy over that

1180 achievable using existing measurements. For example, acquiring diffusion-weighted ASL at

1181 multiple echo times may help to better define label location, and therefore $k_{\text {in }}$ [113].

1182 Furthermore, simultaneously measuring the effect of exchange on $T_{1}$ and $T_{2}$ in contrast

1183 agent based methods (e.g. using a steady state free-precession sequence) may also help

1184 [114]. Since $T_{2}$ relaxation rates are inherently 1-2 orders of magnitude greater than $T_{1}$

1185 relaxation rates, much faster water exchange is required to average compartmental

1186 relaxation rates, than for $T_{1}$. This means that very fast exchange rates, as may be present in 
1187 cases of severe BBB breakdown, and which would be difficult to measure precisely with $T_{1}$

1188 contrast alone, may be more precisely measured via their effect on $T_{2}$.

1189 In conclusion, MRI measurements of BBB water exchange have already contributed

1190 significantly to understanding of BBB dysfunction across a range of disease settings. Future

1191 work should aim to improve the repeatability of these measurements, such that they can be

1192 used to better understand the timing and origin of BBB dysfunction, and to study to the effect

1193 of these changes on the brain.

1194

1195 Funding: the lead author is funded by Medical Research Council Confidence in Concept 1196 Funding. 


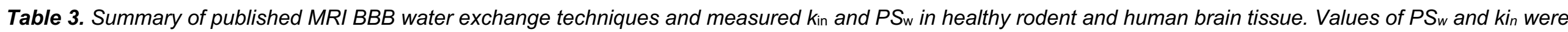

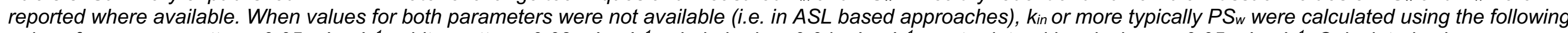

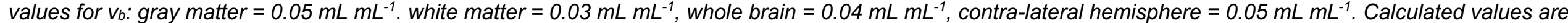
denoted with $t$.

\begin{tabular}{|c|c|c|c|c|c|c|c|}
\hline Author & Technique & Sequence & Acquisition parameters & Subjects & $k_{\text {in }}\left(\min ^{-1}\right)$ & ${ }_{1}^{P S_{w}}\left(m L \min ^{-1} m L^{-}\right.$ & $\begin{array}{l}\text { Kinetic } \\
\text { model }\end{array}$ \\
\hline \multicolumn{8}{|c|}{ Contrast agent based methods } \\
\hline $\begin{array}{l}\text { Schwarzbauer } \\
\text { et al. } \\
\text { (1997)[26] }\end{array}$ & Dose ramping & $\begin{array}{l}2 D I R \\
\text { turboFLASH }\end{array}$ & $\begin{array}{l}7 T, \text { axial, TR/TE }=2.6 / 1.4 \mathrm{~ms}, \sigma=5^{\circ}, \mathrm{TI} \\
=n^{*} 170 \mathrm{~ms}(n=1-16), \text { voxel size }=0.27 x \\
0.55 \times 2 \mathrm{~mm} \text {, single slice, NSA }=16, \mathrm{Gd}- \\
\text { DTPA-Polylysine }\end{array}$ & $\begin{array}{l}5 \text { healthy female } \\
\text { Lewis rats }\end{array}$ & $\begin{array}{l}207 \text { (cortex) } \\
102 \text { (hippocampus) } \\
638 \text { (jaw muscle) }\end{array}$ & $\begin{array}{l}3.31 \text { (cortex) } \\
3.37 \text { (hippocampus) } \\
10.6 \text { (jaw muscle) }\end{array}$ & $\begin{array}{l}\text { Simplified } \\
2 C X M\end{array}$ \\
\hline $\begin{array}{l}\text { Kim et al. } \\
\text { (2008)[29] }\end{array}$ & $\begin{array}{l}\text { Water } \\
\text { exchange } \\
\text { index (WEI) }\end{array}$ & $3 D S P G R$ & $\begin{array}{l}9.4 T, \text { axial, } T R / T E=40 / 4 \mathrm{~ms}, \sigma=20^{\circ}, \\
40^{\circ}, 60^{\circ}, 90^{\circ}, \text { voxel size }=0.25 \times 0.25 \times \\
0.25 \mathrm{~mm}, \mathrm{Gd}-P G C\end{array}$ & $\begin{array}{l}5 \text { healthy male } \\
\text { mice, aged } 8 \text { wo }\end{array}$ & $N / A$ & $N / A$ & $\begin{array}{l}\text { Blood volume } \\
\text { model }\end{array}$ \\
\hline $\begin{array}{l}\text { Anderson et al. } \\
\text { (2013)[27] }\end{array}$ & First pass & $\begin{array}{l}2 D \\
\text { TurboFLASH }\end{array}$ & $\begin{array}{l}7 T, \text { axial, } T R / T E=\text { unreported, flip angle } \\
=\text { unreported, FOV = unreported, matrix } \\
=\text { unreported, gadoteriodol }\end{array}$ & $\begin{array}{l}71 \text { yo female } \\
\text { with early } A D\end{array}$ & $186(W M)$ & $2.3(W M)$ & $\begin{array}{l}\text { Simplified } \\
2 C X M\end{array}$ \\
\hline $\begin{array}{l}\text { Dickie et al. } \\
\text { (2019)[31] }\end{array}$ & $\begin{array}{l}\text { Multi-flip angle } \\
\text { multi-echo } \\
\text { (MFAME)-MRI }\end{array}$ & $\begin{array}{l}3 D \text { multi- } \\
\text { gradient echo } \\
\text { SPGR }\end{array}$ & $\begin{array}{l}7 T, \text { axial, TR/TE }=100 / 2 \mathrm{~ms} \\
10 \text { echoes; } \triangle T E=2 \mathrm{~ms}, \sigma=10^{\circ}, 20^{\circ} \\
30^{\circ}, 40^{\circ}, 80^{\circ}, \text { voxel size }=0.94 \times 0.94 \times \\
0.94 \mathrm{~mm}, 30 \text { slices, Gd-DOTA }\end{array}$ & $\begin{array}{l}5 \text { healthy male } \\
\text { Fisher } 344 \text { rats } \\
\text { aged } 18 \text { mo }\end{array}$ & $\begin{array}{l}171 \text { (hippocampus) } \\
70 \text { (cortex) } \\
128 \text { (striatum) } \\
42 \text { (thalamus) } \\
\text { *unpublished data }\end{array}$ & $\begin{array}{l}4.9 \text { (hippocampus) } \\
2.7 \text { (cortex) } \\
3.5 \text { (striatum) } \\
2.6 \text { (thalamus) }\end{array}$ & $2 C X M$ \\
\hline
\end{tabular}




\begin{tabular}{|c|c|c|c|c|c|c|c|}
\hline $\begin{array}{l}\text { Zaharchuk et } \\
\text { al. (1998)[76] }\end{array}$ & CAPTIVE MRI & $\begin{array}{l}\text { Pre- and } \\
\text { post-contrast } \\
\text { ASL }\end{array}$ & $\begin{array}{l}4.7 T, \text { axial, } T R / T E=4000 / 40 \mathrm{~ms} \text {, voxel } \\
\text { size }=0.78 \times 0.78 \times 2 \mathrm{~mm} \text {, single slice, } \\
\text { pulse duration }=3.7 \mathrm{~s}, P L D=0.2 \mathrm{~s}, \\
\text { MPEG-PL-Dy-DTPA }\end{array}$ & $\begin{array}{l}10 \text { healthy } \\
\text { Sprague Dawley } \\
\text { rats }\end{array}$ & 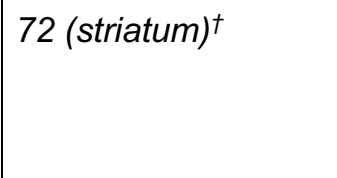 & 2.9 (striatum) & $2 C X M$ \\
\hline $\begin{array}{l}\text { Beaumont et } \\
\text { al. (2016)[77] }\end{array}$ & $\begin{array}{l}\text { Contrast- } \\
\text { enhanced ASL }\end{array}$ & $\begin{array}{l}\text { Pre- and } \\
\text { post-contrast } \\
\text { ASL (STAR } \\
\text { with look- } \\
\text { locker } \\
\text { readout) }\end{array}$ & $\begin{array}{l}3 T, \text { axial, TR/TE }=4000 / 11 \mathrm{~ms}, \text { voxel } \\
\text { size }=3.5 \times 3.5 \times 7 \mathrm{~mm}, 11 \text { slices, slice } \\
\text { gap }=1 \mathrm{~mm}, 11 \text { PLDs }=300-3300 \mathrm{~ms}, \\
\text { NEX }=60\end{array}$ & $\begin{array}{l}1 \text { healthy human } \\
\text { subject }\end{array}$ & 38 (GM) & $1.5(G M)^{\dagger}$ & $2 C X M$ \\
\hline \multicolumn{8}{|c|}{ Non-contrast agent methods } \\
\hline $\begin{array}{l}\text { Parkes et al. } \\
(2002)[43]\end{array}$ & $A S L$ & $\begin{array}{l}\text { CASL with } \\
\text { GE-EPI }\end{array}$ & $\begin{array}{l}1.5 \mathrm{~T}, \mathrm{TR} / \mathrm{TE}=4000 / 34 \mathrm{~ms}, \text { voxel size }= \\
3.75 \times 3.75 \times 7 \mathrm{~mm}, 7 \text { slices, } P L D \mathrm{~s}=0- \\
1500 \mathrm{~ms} \text {, labeling duration }=1.7 \mathrm{~s}, \mathrm{NEX}= \\
45\end{array}$ & $\begin{array}{l}3 \text { healthy female } \\
\text { humans, mean } \\
\text { age } 28 \text { yo }\end{array}$ & $\begin{array}{l}19(G M) \\
2.9(W M)\end{array}$ & $\begin{array}{l}0.95(G M)^{\dagger} \\
0.087(W M)^{\dagger}\end{array}$ & $2 C X M$ \\
\hline $\begin{array}{l}\text { Carr et al. } \\
\text { (2007)[41] }\end{array}$ & $A S L$ & FAIR & $\begin{array}{l}9.4 T, \text { voxel size }=\text { not reported. single } \\
\text { slice, slice thickness }=2 \mathrm{~mm}, 7 \mathrm{PLDs}= \\
1000-5000 \mathrm{~ms}, \mathrm{NEX}=6\end{array}$ & 4 healthy rats & Not measurable & Not measurable & $2 C X M$ \\
\hline $\begin{array}{l}\text { Wells et al. } \\
\text { (2013)[47] }\end{array}$ & Multi-TE ASL & $\begin{array}{l}\text { PASL (FAIR) } \\
\text { with two-shot } \\
\text { segmented } \\
\text { SE-EPI }\end{array}$ & $\begin{array}{l}9.4 T, T R=2500 / 19-60 \mathrm{~ms}, 16 \mathrm{TEs}, \text { voxel } \\
\text { size }=0.55 \times 0.55 \times 2 \mathrm{~mm} \text {, single slice, } \\
\text { NEX }=5, P L D s=1000,1500,2000 \\
2500 \mathrm{~ms}\end{array}$ & $\begin{array}{l}9 \text { healthy male } \\
\text { Sprague Dawley } \\
\text { rats }\end{array}$ & $\begin{array}{l}162 \text { (cortex) } \\
{ }^{*} \text { calculated by } \\
\text { taking the inverse of } \\
T_{\text {ex }}\end{array}$ & $8.1(\text { cortex })^{+}$ & $\begin{array}{l}\text { Kety }+ \\
\text { vascular } \\
\text { compartment }\end{array}$ \\
\hline $\begin{array}{l}\text { Gregori et al. } \\
\text { (2013)[48] }\end{array}$ & Multi-TE ASL & $\begin{array}{l}\text { PCASL } \\
\text { (FAIR) } \\
\text { with } 3 D \\
\text { GRASE }\end{array}$ & $\begin{array}{l}3 T, \text { axial, } T R=3800 \mathrm{~ms}, \text { TEs }=16.5 \\
49.4,82.3,20, \text { voxel size }=3 \times 3 \times 4 \mathrm{~mm} \\
26 \text { slice, } P L D s=150-3000 \mathrm{~ms}\end{array}$ & $\begin{array}{l}5 \text { healthy human } \\
\text { volunteers aged } \\
\text { between } 24 \text { and } \\
36 \text { yo }\end{array}$ & 137 (GM) & $6.9(G M)^{\dagger}$ & $\begin{array}{l}\text { Kety }+ \\
\text { vascular } \\
\text { compartment }\end{array}$ \\
\hline
\end{tabular}




\begin{tabular}{|c|c|c|c|c|c|c|c|}
\hline $\begin{array}{l}\text { Ohene et al. } \\
(2018)[115]\end{array}$ & Multi-TE ASL & $\begin{array}{l}\text { PCASL } \\
\text { (FAIR) with } \\
\text { segmented } \\
2 D \text { SE-EPI }\end{array}$ & $\begin{array}{l}9.4 T, \text { axial, } T R=5000 \mathrm{~ms}, T E s=15,23 \\
30,40,50,65 \mathrm{~ms}, \text { voxel size }=0.78 \times \\
0.78 \times 16 \mathrm{~mm}, \text { single slice, } P L D s=400 \\
1000,1500,3500 \mathrm{~ms}, \mathrm{NEX}=20\end{array}$ & $\begin{array}{l}9 \text { male C57/BL6 } \\
\text { mice aged } 6 \text { mo }\end{array}$ & $\begin{array}{l}174 \text { (cortex) } \\
{ }^{*} \text { calculated by } \\
\text { taking the inverse of } \\
T_{\text {ex }}\end{array}$ & $8.7(\text { cortex })^{\dagger}$ & $\begin{array}{l}\text { Kety }+ \\
\text { vascular } \\
\text { compartment }\end{array}$ \\
\hline $\begin{array}{l}\text { Silva et al. } \\
\text { (1997a)[70] }\end{array}$ & $\begin{array}{l}\text { Diffusion } \\
\text { weighted ASL }\end{array}$ & $\begin{array}{l}\text { Adiabatic fast } \\
\text { passage } \\
\text { inversion ASL } \\
\text { with PGSE }\end{array}$ & $\begin{array}{l}4.7 T, T E=47 \mathrm{~ms}, P L D=0, b=0-1739 \\
\text { in } 12 \text { steps, no in plane location, label } \\
\text { duration }=3.5 \mathrm{~s}\end{array}$ & $\begin{array}{l}12 \text { healthy male } \\
\text { Sprague-Dawley } \\
\text { rats }\end{array}$ & 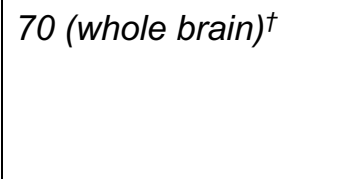 & $\begin{array}{l}2.8 \text { (whole brain) } \\
{ }^{*} \text { calculated from } E= \\
0.85 \text { and } C B F=145 \\
m L \text { min }^{-1} g^{-1}\end{array}$ & $\begin{array}{l}\text { IVIM } f \\
\text { assumed to } \\
\text { be equal to } E\end{array}$ \\
\hline $\begin{array}{l}\text { Wang et al. } \\
\text { (2007)[71] }\end{array}$ & $\begin{array}{l}\text { Diffusion } \\
\text { weighted ASL }\end{array}$ & $\begin{array}{l}\text { Amplitude } \\
\text { modulated } \\
\text { DW-CASL }\end{array}$ & $\begin{array}{l}3 T, \text { axial, } T R / T E=4000-4500 / 55-60 \mathrm{~ms} \\
\text { voxel size }=3.4 \times 3.4 \times 8 \mathrm{~mm}, 6 \text { slices, } \\
P L D \mathrm{~s}=0.8,1.2,1.5 \mathrm{~s}, b=0,10,25,50 \\
100,150,200,300 \mathrm{smm}\end{array}$ & $\begin{array}{l}13 \text { healthy } \\
\text { humans ( } 6 \\
\text { women, } 7 \text { men) } \\
\text { aged } 26.4 \text { yo }\end{array}$ & 193 (GM) & $9.7(G M)^{\dagger}$ & $\begin{array}{l}\text { SPA } \\
\text { (compartment } \\
\text { model } \\
\text { version) }\end{array}$ \\
\hline $\begin{array}{l}\text { St. Lawrence et } \\
\text { al. (2012)[72] }\end{array}$ & $\begin{array}{l}\text { Diffusion } \\
\text { weighted ASL }\end{array}$ & $\begin{array}{l}\text { Balanced } \\
\text { DW-pCASL }\end{array}$ & $\begin{array}{l}3 T, \text { axial, TR/TE }=4000 / 48 \mathrm{~ms} \\
\text { voxel size }=3.4 \times 3.4 \times 8 \mathrm{~mm}, 8 \text { slices, } \\
P L D=1500 \mathrm{~ms}, b=0,50 \mathrm{~s} / \mathrm{mm}^{2}\end{array}$ & $\begin{array}{l}7 \text { healthy human } \\
\text { subjects ( } 3 \\
\text { female, } 4 \text { male) } \\
\text { aged } 28 \text { yo }\end{array}$ & $\begin{array}{l}139 \text { (GM), } \\
154(W M)\end{array}$ & $\begin{array}{l}7.0(\mathrm{GM})^{\dagger}, \\
4.6(\mathrm{WM})^{\dagger}\end{array}$ & $\begin{array}{l}\text { SPA } \\
\text { (compartment } \\
\text { model } \\
\text { version) }\end{array}$ \\
\hline $\begin{array}{l}\text { Palomares et } \\
\text { al. (2016)[96] }\end{array}$ & $\begin{array}{l}\text { Diffusion } \\
\text { weighted ASL }\end{array}$ & $D W-p C A S L$ & $\begin{array}{l}3 T, \text { axial, TR/TE }=4300 / 47 \mathrm{~ms}, \text { voxel } \\
\text { size }=3.6 \times 3.6 \times 3.5 \mathrm{~mm}, 38 \mathrm{slices}, P L D \\
=1500 \mathrm{~ms}, \mathrm{NEX}=80, b=0,50 \mathrm{~s} / \mathrm{mm}^{2}\end{array}$ & $\begin{array}{l}9 \text { healthy human } \\
\text { subjects (4 } \\
\text { female, } 5 \text { male) } \\
\text { aged } 38.8 \text { yo }\end{array}$ & $\begin{array}{l}221 \text { (GM), } \\
261 \text { (WM) }\end{array}$ & $\begin{array}{l}11(\mathrm{GM})^{\dagger} \\
7.8(W M)^{\dagger}\end{array}$ & $\begin{array}{l}\text { SPA } \\
\text { (compartment } \\
\text { model } \\
\text { version) }\end{array}$ \\
\hline $\begin{array}{l}\text { Tiwari et al. } \\
\text { (2017)[94] }\end{array}$ & $\begin{array}{l}\text { Diffusion } \\
\text { weighted ASL }\end{array}$ & $D W-p C A S L$ & $\begin{array}{l}7 T, T R / T E=3000 / 28 \mathrm{~ms}, 4 \times 4 \times 3 \mathrm{~mm}, 4 \\
\text { slices, } P L D=400 \mathrm{~ms}^{-N} \mathrm{NEX}=60, \mathrm{~b} \\
\left.\text { values }=0,50 \mathrm{~s} \mathrm{mm^{-2 }} \text { (along } \mathrm{z}\right)\end{array}$ & $\begin{array}{l}12 \text { male healthy } \\
\text { Sprague Dawley } \\
\text { rats aged } 8-10 \\
\text { wo }\end{array}$ & $\begin{array}{l}363 \text { (contra-lesional } \\
\text { hemisphere) }\end{array}$ & $\begin{array}{l}18 \text { (contra-lesional } \\
\text { hemisphere) }^{\dagger}\end{array}$ & $\begin{array}{l}\text { SPA } \\
\text { (compartment } \\
\text { model } \\
\text { version) }\end{array}$ \\
\hline $\begin{array}{l}\text { Shao et al. } \\
(2018)[116]\end{array}$ & $\begin{array}{l}\text { Diffusion } \\
\text { weighted ASL }\end{array}$ & $\begin{array}{l}D W-p C A S L \\
\text { with } 3 D \\
\text { GRASE }\end{array}$ & $\begin{array}{l}3 T, \text { axial, } T R / T E=4000 / 36.5 \mathrm{~ms}, \text { voxel } \\
\text { size }=3.5 \times 3.5 \times 8 \mathrm{~mm}, \text { slices }=12, b= \\
50 \mathrm{smm} \mathrm{mm}^{-2}, P L D=1800 \mathrm{~ms}\end{array}$ & $\begin{array}{l}19 \text { elderly } \\
\text { subjects }(7 \\
\text { male, } 12 \\
\text { female), mean } \\
\text { age } 68.8 \text { yo }\end{array}$ & $\begin{array}{l}109(\mathrm{GM}) \\
94.1(W M)\end{array}$ & $\begin{array}{l}5.5(G M)^{\dagger} \\
2.8(W M)^{\dagger}\end{array}$ & $\begin{array}{l}\text { Regularised } \\
\text { SPA }\end{array}$ \\
\hline $\begin{array}{l}\text { Wengler et al. } \\
\text { (2019)[74] }\end{array}$ & $\begin{array}{l}\text { Intrinsic } \\
\text { diffusivity } \\
\text { encoding of }\end{array}$ & $\begin{array}{l}\text { pCASL with } \\
3 D \\
\text { segmented } \\
\text { GRASE }\end{array}$ & $\begin{array}{l}3 T, \text { axial, } T R / T E=4500 / 16 \mathrm{~ms}, \sigma=120^{\circ} \\
\text { voxel size }=4 \times 4 \times 4 \mathrm{~mm}, P A R \text { turbo } \\
\text { factors of } 12 \text { and } 48, P L D=2000 \mathrm{~m}\end{array}$ & $\begin{array}{l}15 \text { healthy } \\
\text { subjects ( } 8 \\
\text { male, } 7 \text { female) }\end{array}$ & $\begin{array}{l}171(\mathrm{GM}) \\
146(W M) \\
{ }^{*} \mathrm{using} \mathrm{T}_{b}=350 \mathrm{~ms} \\
\text { and } 410 \mathrm{~ms}\end{array}$ & $\begin{array}{l}1.3(G M) \\
0.76(G M)\end{array}$ & $\begin{array}{l}\text { Regularised } \\
\text { SPA }\end{array}$ \\
\hline
\end{tabular}




\begin{tabular}{|c|c|c|c|c|c|c|c|}
\hline & $\begin{array}{l}\text { arterial labelled } \\
\text { spin (IDEALS) }\end{array}$ & & & & $\begin{array}{l}\text { respectively as per } \\
\text { paper }\end{array}$ & & \\
\hline $\begin{array}{l}\text { Silva et al. } \\
\text { (1997b)[75] }\end{array}$ & $\begin{array}{l}\text { Magnetisation } \\
\text { transfer } \\
\text { weighted ASL }\end{array}$ & $\begin{array}{l}\text { Volume } \\
\text { localised } \\
\text { STEAM }\end{array}$ & $\begin{array}{l}4.7 T, \text { coronal, } T R=\text { unreported, } T E=30 \\
m s, \text { voxel size = unreported, }\end{array}$ & $\begin{array}{l}25 \text { healthy } \\
\text { Sprague Dawley } \\
\text { rats }\end{array}$ & Not measured & Not measured & $2 C X M$ \\
\hline $\begin{array}{l}\text { Hales et } \\
\text { al.[117] }\end{array}$ & $I V I M+A S L$ & $\begin{array}{l}\text { Separate } 2 D \\
\text { EPI (diffusion) } \\
\text { and pCASL } \\
\text { (FAIR) with } \\
\text { GRASE } \\
\text { readout (ASL) }\end{array}$ & $\begin{array}{l}\text { 1.5T, axial, voxel size }=3.6 \times 3.6 \times 5 \\
m m, 20 \text { slices, } N E X=8 . \\
\text { ASL: TR/TE }=3000 / 31.6 \mathrm{~ms}, \\
P L D s=0.2,0.4,0.6,0.8,1.0,1.2,1.4 \\
1.6,1.8,2.0,2.2,2.4 \mathrm{~s} . \\
D W-M R I: T R / T E=3800 / 120, b=0,20, \\
40,80,120,, 160,200,300,500,1000 \\
s / m^{2}\end{array}$ & $\begin{array}{l}10 \text { healthy } \\
\text { human subjects } \\
(4 \text { female, } 6 \\
\text { male) mean age } \\
27 \text { years }\end{array}$ & $48(G M)^{\dagger}$ & $1.1(G M)$ & $\begin{array}{l}\text { IVIM } \\
\text { (diffusion } \\
\text { data) and } \\
\text { four-phase } \\
\text { single } \\
\text { capillary } \\
\text { stepwise } \\
\text { model (ASL } \\
\text { data) }\end{array}$ \\
\hline $\begin{array}{l}\text { Lin et al. } \\
(2018)[118]\end{array}$ & $\begin{array}{l}\text { Phase-contrast } \\
\text { (WEPCAST) } \\
\text { ASL }\end{array}$ & $\begin{array}{l}\text { ASL with } \\
\text { phase- } \\
\text { contrast } \\
\text { velocity- } \\
\text { encoding } \\
\text { gradients }\end{array}$ & $\begin{array}{l}3 T, \text { sagittal, TR/TE }=7546 / 9.2 \mathrm{~ms}, \text { voxel } \\
\text { size }=3.1 \times 3.1 \times 10, \text { single slice placed } \\
\text { midway through the brain, } P L D \mathrm{~s}=1500, \\
2000,2500,3000,3500,4000,4500, \\
\text { and } 5000 \mathrm{~ms}, \text { label duration }=2000 \mathrm{~ms}, \\
V_{\text {enc }}=15 \mathrm{~cm} / \mathrm{s}, \mathrm{NEX}=10\end{array}$ & $\begin{array}{l}6 \text { healthy human } \\
\text { participants (3 } \\
\text { female, } 3 \text { male) } \\
\text { mean age } 27 \\
\text { years }\end{array}$ & 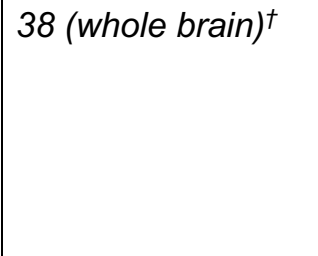 & 1.9 (whole brain) & $\begin{array}{l}\text { Venous } \\
\text { model } \\
\text { incorporating } \\
\text { extraction and } \\
\text { dispersion }\end{array}$ \\
\hline
\end{tabular}

Table 4. Mean kin (and s.e.m) and PS (and s.e.m) in healthy human and rodent brain. Data from Li et al. [51] and Tiwari et al. [94] were treated as extreme values and excluded. When not measured, values for PS were calculated as described in the legend of Table 3.

\begin{tabular}{|l|l|l|l|}
\hline & Human gray matter $(\boldsymbol{n}=\mathbf{7})$ & Human white matter $(\boldsymbol{n}=\mathbf{5})$ & Rodent gray matter $(\boldsymbol{n}=\mathbf{4})$ \\
\hline$k_{\text {in }}\left(\mathrm{min}^{-1}\right)$ & $159(14)$ & $165(27)$ & $148(16)$ \\
\hline$P S_{w}\left(\mathrm{~mL} \mathrm{~min}^{-1} \mathrm{~mL}^{-1}\right)$ & $6.6(1.2)$ & $3.6(1.4)$ & $5.9(1.5)$ \\
\hline
\end{tabular}




\begin{tabular}{|c|c|c|c|}
\hline Author & MRI Technique & Subjects & Findings \\
\hline Li et al. (2005) & ASL & Healthy subjects with different ages $(n=8)$ & Trend towards decreasing $k_{w}$ with age \\
\hline $\begin{array}{l}\text { Kim et al. } \\
(2008)[29]\end{array}$ & Water exchange index & $\begin{array}{l}\text { Surgical model of middle cerebral artery occlusion } \\
(M C A O) \text { in male C57BL/6 mice }(n=5) \text { and controls }(n= \\
\text { 4). }\end{array}$ & $\begin{array}{l}\text { WEl elevated in ipsilesional cortex between 1-4 hours after } \\
\text { MCAo }\end{array}$ \\
\hline $\begin{array}{l}\text { Huang et al. } \\
\text { (2013)[60] }\end{array}$ & Water exchange index & $\begin{array}{l}\text { Acute transient stroke model in male C57BL/6 mice } \\
\text { (stroke, } n=15 ; \text { controls, } n=6 \text { ) }\end{array}$ & $\begin{array}{l}\text { WEl in ipsilesional cortex increased by } 1.97 \text { in controls to } \\
4.67 \text { in stroke mice. Approximately } 33 \% \text { of mice did not } \\
\text { exhibit any change however. }\end{array}$ \\
\hline $\begin{array}{l}\text { Dickie et al. } \\
\text { (2019)[31] }\end{array}$ & MFAME-MRI & $\begin{array}{l}\text { Transgenic rat model of Alzheimer's disease ( } n=7 \\
\text { TgF344-AD, } n=5 \text { wild-types). }\end{array}$ & $\begin{array}{l}P S_{w} \text { increased in } A D \text { rats relative to wild-types ( } k_{\text {in }} \\
\text { increased in } A D \text { rats - results not published). }\end{array}$ \\
\hline $\begin{array}{l}\text { Rooney et al. } \\
\text { (2015)[28] }\end{array}$ & Dose-ramping CE-MRI & Patients with glioblastoma $(n=5,3 M / 2 F, 19-57$ years) & $\begin{array}{l}k_{\text {in }} \text { reduced in tumour }\left(k_{\text {in }}<10 \mathrm{~min}^{-1}\right) \text { relative to normal } \\
\text { appearing grey matter }\left(k_{\text {in }}=192 \mathrm{~min}^{-1}\right) .\end{array}$ \\
\hline $\begin{array}{l}\text { Wang et al. } \\
\text { (2007)[71] }\end{array}$ & $D W-A S L$ & $\begin{array}{l}\text { Patient with brain tumour ( } n=1 \text {, grade } / I \\
\text { oligodendroglioma) }\end{array}$ & $\begin{array}{l}k_{\text {in }} \text { increased in tumour }\left(k_{\text {in }}=463 \mathrm{~min}^{-1}\right) \text { relative to normal } \\
\text { appearing grey matter }\left(k_{\text {in }}=224 \mathrm{~min}^{-1}\right) .\end{array}$ \\
\hline $\begin{array}{l}\text { Rooney et al. } \\
\text { (2015)[28] }\end{array}$ & First-pass CE-MRI & $\begin{array}{l}\text { Relapsing remitting multiple sclerosis }(n=6,2 M / 4 F, 46 \\
( \pm 7) \text { years, } 18-55 \text { years) }\end{array}$ & $\begin{array}{l}k_{\text {in }} \text { reduced in NAGM }\left(k_{\text {in }}=120 \mathrm{~min}^{-1}\right), \text { NAWM }\left(k_{\text {in }}=132\right. \\
\left.\text { min }^{-1}\right) \text {, and lesion }\left(k_{\text {in }}=108 \mathrm{~min}^{-1}\right) \text { relative to healthy } \\
\text { controls }\left(G M ; k_{\text {in }}=174 \mathrm{~min}^{-1}, W M ; k_{\text {in }}=186 \mathrm{~min}^{-1}\right)\end{array}$ \\
\hline $\begin{array}{l}\text { Palomares et al } \\
(2016)[96]\end{array}$ & $D W-A S L$ & $\begin{array}{l}\text { Participants with obstructive sleep apnea }(n=9) \text { and } \\
\text { controls }(n=9)\end{array}$ & $\begin{array}{l}k_{\text {in }} \text { reduced in persons with sleep apnea }\left(G M ; k_{\text {in }}=158 \mathrm{~min}\right. \\
\left.1, W M ; k_{\text {in }}=178 \mathrm{~min}^{-1}\right) \text { relative to controls }\left(G M ; k_{\text {in }}=221\right. \\
\left.\text { min }^{-1}, W M ; k_{\text {in }}=261 \mathrm{~min}^{-1}\right) .\end{array}$ \\
\hline $\begin{array}{l}\text { Shao et al. } \\
(2018)[116]\end{array}$ & $D W-A S L$ & Elderly patients at risk of small vessel disease $(n=19)$ & $\begin{array}{l}\text { kin increased in type-2 diabetes (28.2\% increase), } \\
\text { hypercholestremia (19.5\% increase), and with vascular risk } \\
(\sim 12 \% \text { increase). Kin also predicted sum of box and clinical } \\
\text { dementia ratings. }\end{array}$ \\
\hline
\end{tabular}




\begin{tabular}{|c|c|c|c|c|}
\hline Author & Validation method & MRI technique & Subjects & Findings \\
\hline $\begin{array}{l}\text { Huang et al. } \\
\text { (2013)[60] }\end{array}$ & $\begin{array}{l}\text { Mannitol and hypercapnic } \\
\text { challenge }\end{array}$ & $\begin{array}{l}\text { Water exchange } \\
\text { index }\end{array}$ & $\begin{array}{l}\text { Male C57BL/6 mice (mannitol, } n= \\
7 ; \mathrm{CO}_{2}, n=6 \text { ) }\end{array}$ & $\begin{array}{l}\text { Mannitol increased WEI and CBV as early as } 15 \text { minutes } \\
\text { post injection. Hypercapnia }\left(2.5 \%-10 \% \mathrm{CO}_{2}\right) \text { also increased } \\
\text { WEI and CBV. }\end{array}$ \\
\hline $\begin{array}{l}\text { Zaharchuk et al. } \\
\text { (1998)[76] }\end{array}$ & Hypercapnic challenge & CAPTIVE MRI & Sprague Dawley rats $(n=10)$ & Hypercapnia reduced extraction fraction. $P S_{w}$ unaffected. \\
\hline $\begin{array}{l}\text { Silva et al. } \\
(1997 a)[70]\end{array}$ & Hypercapnic challenge & $\begin{array}{l}\text { Diffusion weighted } \\
\text { ASL }\end{array}$ & $\begin{array}{l}\text { Male Sprague Dawley rats }(n= \\
\text { 12) }\end{array}$ & Hypercapnia reduced extraction fraction. \\
\hline $\begin{array}{l}\text { Silva et al. } \\
(1997 b)[75]\end{array}$ & Mannitol challenge & $\begin{array}{l}\text { Magnetisation } \\
\text { transfer weighted } \\
\text { ASL }\end{array}$ & Sprague Dawley rats $(n=7)$ & Mannitol increased water-extraction fraction \\
\hline $\begin{array}{l}\text { Dickie et al. } \\
(2019)[31]\end{array}$ & $\begin{array}{l}\text { Immunofluorescence staining } \\
\text { for occludin, claudin-5, } \\
\text { aquaporin-4 and lectin. }\end{array}$ & MFAME-MRI & $\begin{array}{l}\text { Transgenic Alzheimer's disease } \\
\text { rats }(T g F 344-A D, n=7) \text { and wild- } \\
\text { types }(n=5)\end{array}$ & $\begin{array}{l}\text { Significant inverse correlation between } P S_{w} \text { and tight } \\
\text { junction protein expression (occludin). }\end{array}$ \\
\hline $\begin{array}{l}\text { Ohene et al. } \\
\text { (2019)[115] }\end{array}$ & AQP4-null knockout mice & Multi-TE ASL & $\begin{array}{l}\text { Male AQP4 null mice }(n=9) \text { and } \\
\text { C57/BL6 wild-types }(n=9)\end{array}$ & $\begin{array}{l}\text { Significant reduction in } k_{\text {in }} \text { in AQP4 null mice relative to wild- } \\
\text { types }\left(132 \mathrm{~min}^{-1} \text { versus } 172 \mathrm{~min}^{-1}\right)\end{array}$ \\
\hline
\end{tabular}




\section{Bibliography}

[1] A. Armulik, G. Genové, M. Mäe, M.H. Nisancioglu, E. Wallgard, C. Niaudet, L. He, J. Norlin, P. Lindblom, K. Strittmatter, B.R. Johansson, C. Betsholtz, Pericytes regulate the blood-brain barrier., Nature. 468 (2010) 557-561. doi:10.1038/nature09522.

[2] R. Daneman, L. Zhou, A.A. Kebede, B.A. Barres, Pericytes are required for bloodbrain barrier integrity during embryogenesis, Nature. 468 (2010) 562-566. doi:10.1038/nature09513.

[3] G. Li, W. Yuan, B.M. Fu, A model for the blood-brain barrier permeability to water and small solutes, J. Biomech. 43 (2010) 2133-2140. doi:10.1016/j.jbiomech.2010.03.047.

[4] P. Beard, Biomedical photoacoustic imaging, Interface Focus. 1 (2011) 602-631. doi:10.1098/rsfs.2011.0028.

[5] M. Piert, R. a Koeppe, B. Giordani, S. Berent, D.E. Kuhl, Diminished glucose transport and phosphorylation in Alzheimer's disease determined by dynamic FDG-PET., J. Nucl. Med. 37 (1996) 201-208.

[6] S. Syvänen, J. Eriksson, Advances in PET imaging of P-glycoprotein function at the blood-brain barrier, ACS Chem. Neurosci. 4 (2013) 225-237. doi:10.1021/cn3001729.

[7] F.A. Nasrallah, G. Pagès, P.W. Kuchel, X. Golay, K.H. Chuang, Imaging brain deoxyglucose uptake and metabolism by glucoCEST MRI, J. Cereb. Blood Flow Metab. 33 (2013) 1270-1278. doi:10.1038/jcbfm.2013.79.

[8] A.K. Heye, R.D. Culling, M. del C. Valdés Hernández, M.J. Thrippleton, J.M. Wardlaw, Assessment of blood-brain barrier disruption using dynamic contrast-enhanced MRI. A systematic review, Neurolmage Clin. 6 (2014) 262-274. doi:10.1016/j.nicl.2014.09.002.

[9] A.K. Heye, M.J. Thrippleton, P.A. Armitage, M. del C. Valdés Hernández, S.D. Makin, A. Glatz, E. Sakka, J.M. Wardlaw, Tracer kinetic modelling for DCE-MRI quantification of subtle blood-brain barrier permeability, Neuroimage. 125 (2016) 446-455. doi:10.1016/j.neuroimage.2015.10.018.

[10] P.A. Armitage, A.J. Farrall, T.K. Carpenter, F.N. Doubal, J.M. Wardlaw, Use of 
dynamic contrast-enhanced MRI to measure subtle blood-brain barrier abnormalities, Magn. Reson. Imaging. 29 (2011) 305-314. doi:10.1016/j.mri.2010.09.002.

[11] T. Nitta, M. Hata, S. Gotoh, Y. Seo, H. Sasaki, N. Hashimoto, M. Furuse, S. Tsukita, Size-selective loosening of the blood-brain barrier in claudin-5-deficient mice, J. Cell Biol. 161 (2003) 653-660. doi:10.1083/jcb.200302070.

[12] H. Fischer, R. Gottschlich, A. Seelig, Blood-brain barrier permeation: Molecular parameters governing passive diffusion, J. Membr. Biol. 165 (1998) 201-211. doi:10.1007/s002329900434.

[13] J.O. Eichling, M.E. Raichle, R.L. Grubb, M.M. Ter Pogossian, Evidence of the limitations of water as a freely diffusible tracer in brain of the rhesus monkey, Circ. Res. 35 (1974) 358-364. doi:10.1161/01.RES.35.3.358.

[14] T.G. Bolwig, N.A. Lassen, The Diffusion Permeability to Water of the Rat Blood-Brain Barrier, Acta Physiol. Scand. 93 (1975) 415-422. doi:10.1111/j.17481716.1975.tb05831.x.

[15] O.. Paulson, M.. Hertz, T.. Bolwig, N.. Lassen, Filtration and Diffusion of Water Across Brain Barrier in Man, Microvasc. Res. 124 (1977) 113-123.

[16] W.M. Pardridge, G. Fierer, Blood-Brain Barrier Transport of Butanol and Water Relative to N-Isopropyl-p-iodoamphetamine as the Internal Reference, J. Cereb. Blood Flow Metab. 5 (1985) 275-281.

[17] S. Takagi, K. Ehara, R.D. Finn, Water extraction fraction and permeability-surface product after intravenous injection in rats, Stroke. 18 (1987) 177-183. doi:10.1161/01.STR.18.1.177.

[18] P. Herscovitch, M.E. Raichle, M.R. Kilbourn, M.J. Welch, Positron emission tomographic measurement of cerebral blood flow and permeability-surface area product of water using and 2 over black square]; [ 1 and 2 over black square]50]water and and 2 over black square]; [1 and 2 over black square]1C]butanol, J. Cereb. Blood Flow Metab. 7 (1987) 527-542.

[19] T. Zeuthen, Water-Transporting Proteins, (2010) 57-73. doi:10.1007/s00232-009- 
9216-y.

[20] C. Crone, The Permeability of Capillaries in Various Organs as Determined by Use of the ???Indicator Diffusion??? Method, Acta Physiol. Scand. 58 (1963) 292-305. doi:10.1111/j.1748-1716.1963.tb02652.x.

[21] E. Renkin, Transport of potassium-42 from blood to tissue in isolated mammalian skeletal muscles, Am J Physiol. 197 (1959) 1205-1210.

http://ajplegacy.physiology.org/content/197/6/1205.abstract\%5Cnhttp://ajplegacy.phys iology.org/content/197/6/1205.abstract?sid=586b9277-9912-41a8-93a42e126ea90447.

[22] M.S. Berridge, L.P. Adler, A.D. Nelson, E.H. Cassidy, R.F. Muzic, E.M. Bednarczyk, F. Miraldi, Measurement of human cerebral blood flow with [150]butanol and positron emission tomography, J. Cereb. Blood Flow Metab. 11 (1991) 707-715. doi:10.1038/jcbfm.1991.127.

[23] M.E. Raichle, J.O. Eichling, M.G. Straatmann, M.J. Welsh, K.B. Larson, M.M. TerPogossian, Blood-brain barrier permeability alcohols and 150-labeled water, Am. J. Physiol. 230 (1976).

[24] M.E. Fabry, M. Eisenstadt, Water exchange between red cells and plasma. Measurement by nuclear magnetic relaxation, Biophys. J. 15 (1975) 1101-1110. doi:10.1016/S0006-3495(75)85886-3.

[25] T. Conlon, R. Outhred, Water diffusion permeability of erythrocytes using an NMR technique, BBA - Biomembr. 288 (1972) 354-361. doi:10.1016/0005-2736(72)902568.

[26] C. Schwarzbauer, S.P. Morrissey, R. Deichmann, C. Hillenbrand, J. Syha, H. Adolf, U. Nöth, A. Haase, Quantitative magnetic resonance imaging of capillary water permeability and regional blood volume with an intravascular $\{M R\}$ contrast agent., Magn Reson Med. 37 (1997) 769-777.

[27] V.C. Anderson, D.P. Lenar, J.F. Quinn, W.D. Rooney, The blood-brain barrier and microvascular water exchange in Alzheimer's disease., Cardiovasc. Psychiatry 
Neurol. 2011 (2011) 615829. doi:10.1155/2011/615829.

[28] W.D. Rooney, X. Li, M.K. Sammi, D.N. Bourdette, E. a Neuwelt, C.S. Springer, Mapping human brain capillary water lifetime: high-resolution metabolic neuroimaging., NMR Biomed. 28 (2015) 607-23. doi:10.1002/nbm.3294.

[29] Y.R. Kim, E. Tejima, S. Huang, D.N. Atochin, G. Dai, E.H. Lo, P.L. Huang, A. Bogdanov, B.R. Rosen, In vivo quantification of transvascular water exchange during the acute phase of permanent stroke., Magn. Reson. Med. 60 (2008) 813-21. doi:10.1002/mrm.21708.

[30] S. Huang, C.T. Farrar, G. Dai, S.J. Kwon, A.A. Bogdanov, B.R. Rosen, Y.R. Kim, Dynamic monitoring of blood-brain barrier integrity using water exchange index (WEI) during mannitol and CO2 challenges in mouse brain, NMR Biomed. 26 (2013) 376385. doi:10.1002/nbm.2871.

[31] B.R. Dickie, M. Vandesquille, J. Ulloa, H. Boutin, L.M. Parkes, G.J.M. Parker, Waterexchange MRI detects subtle blood-brain barrier breakdown in Alzheimer's disease rats, Neuroimage. (2019). doi:10.1016/j.neuroimage.2018.09.030.

[32] C.S. Landis, X. Li, F.W. Telang, P.E. Molina, I. Palyka, G. Vetek, C.S. Springer, Equilibrium transcytolemmal water-exchange kinetics in skeletal muscle in vivo, Magn. Reson. Med. 42 (1999) 467-478. doi:10.1002/(SICI)15222594(199909)42:3<467::AID-MRM9>3.0.CO;2-0.

[33] C.S. Springer, W.D. Rooney, X. Li, The effects of equilibrium transcytolemmal water exchange on the determination of contrast reagent concentration in vivo, Magn. Reson. Med. 47 (2002) 422-424. doi:10.1002/mrm.10099.

[34] D.L. Buckley, Shutter-speed dynamic contrast-enhanced MRI: Is it fit for purpose?, Magn. Reson. Med. 81 (2019) 976-988. doi:10.1002/mrm.27456.

[35] E.L. Barbier, K.S. St Lawrence, E. Grillon, A.P. Koretsky, M. Décorps, A model of blood-brain barrier permeability to water: accounting for blood inflow and longitudinal relaxation effects., Magn. Reson. Med. 47 (2002) 1100-9. doi:10.1002/mrm.10158.

[36] S.S. Kety, The theory and applications of the exchange of inert gas at the lungs and 
tissues., Pharmacol. Rev. 3 (1951) 1-41.

http://www.ncbi.nlm.nih.gov/pubmed/14833874.

[37] D.S. Williams, J.A. Detre, J.S. Leigh, A.P. Koretsky, Magnetic resonance imaging of perfusion using spin inversion of arterial water., Proc. Natl. Acad. Sci. U. S. A. 89 (1992) 212-6. doi:10.1073/pnas.89.9.4220e.

[38] Parkes, Tofts, Improved accuracy of human cerebral blood perfusion measurements using arterial spin labeling: Accounting for capillary water permeability, Magn. Reson. Med. 48 (2002) 27-41. doi:10.1002/mrm.10180.

[39] C.W. Wu, H.L. Liu, J.H. Chen, Y. Yang, Effects of CBV, CBF, and blood-brain barrier permeability on accuracy of PASL and VASO measurement, Magn. Reson. Med. 63 (2010) 601-608. doi:10.1002/mrm.22165.

[40] K.S. St Lawrence, J.A. Frank, A.C. McLaughlin, Effect of restricted water exchange on cerebral blood flow values calculated with arterial spin tagging: A theoretical investigation, Magn. Reson. Med. 44 (2000) 440-449. doi:10.1002/15222594(200009)44:3<440::AID-MRM15>3.0.CO;2-6.

[41] J.P. Carr, D.L. Buckley, J. Tessier, G.J.M. Parker, What levels of precision are achievable for quantification of perfusion and capillary permeability surface area product using ASL?, Magn. Reson. Med. 58 (2007) 281-289. doi:10.1002/mrm.21317.

[42] J. Zhou, D.A. Wilson, J.A. Ulatowski, R.J. Traystman, P.C. van Zijl, Two-compartment exchange model for perfusion quantification using arterial spin tagging., J. Cereb. Blood Flow Metab. 21 (2001) 440-455. doi:10.1097/00004647-200104000-00013.

[43] L.M. Parkes, P.S. Tofts, Improved accuracy of human cerebral blood perfusion measurements using arterial spin labeling: Accounting for capillary water permeability, Magn. Reson. Med. 48 (2002) 27-41. doi:10.1002/mrm.10180.

[44] L.. Parkes, Quantification of Cerebral Perfusion Using Arterial Spin Labeling: TwoCompartment Models, J. Magn. Reson. Imaging. 22 (2005) 732-736. doi:10.1002/jmri.20456. 
[45] K.S. St Lawrence, T.Y. Lee, An adiabatic approximation to the tissue homogeneity model for water exchange in the brain: I. Theoretical derivation, J. Cereb. Blood Flow Metab. Off. J. Int. Soc. Cereb. Blood Flow Metab. 18 (1998) 1365-1377. doi:10.1097/00004647-199812000-00011.

[46] D.C. Alsop, J.A. Detre, Reduced transit-time sensitivity in noninvasive magnetic resonance imaging of human cerebral blood flow, J. Cereb. Blood Flow Metab. 16 (1996) 1236-1249. doi:10.1097/00004647-199611000-00019.

[47] J.A. Wells, B. Siow, M.F. Lythgoe, D.L. Thomas, Measuring biexponential transverse relaxation of the ASL signal at 9.4T to estimate arterial oxygen saturation and the time of exchange, J. Cereb. Blood Flow Metab. 33 (2013) 215-224. http://breast-cancerresearch.biomedcentral.com/articles/10.1186/bcr807.

[48] J. Gregori, N. Schuff, R. Kern, M. Gunther, T2-based Arterial Spin Labeling measurements of blood to tissue water transfer in human brain, J. Magn. Reson. Imaging. 37 (2013) 332-342. doi:10.1002/bmb.20244.DNA.

[49] J. Johnson, T. Wilson, A model for capillary exchange., Am. J. Physiol. 210 (1966) 1299-303. doi:10.1152/ajplegacy.1966.210.6.1299.

[50] K.S. St. Lawrence, T.-Y. Lee, An Adiabatic Approximation to the Tissue Homogeneity Model for Water Exchange in the Brain: II. Experimental Validation, J. Cereb. Blood Flow Metab. 18 (1998) 1378-1385. doi:10.1097/00004647-199812000-00012.

[51] K. Li, X. Zhu, N. Hylton, G.-H. Jahng, M.W. Weiner, N. Schuff, Four-phase singlecapillary stepwise model for kinetics in arterial spin labeling MRI., Magn. Reson. Med. 53 (2005) 511-8. doi:10.1002/mrm.20390.

[52] G.J. Stanisz, E.E. Odrobina, J. Pun, M. Escaravage, S.J. Graham, M.J. Bronskill, R.M. Henkelman, T1, T2 relaxation and magnetization transfer in tissue at 3T, Magn. Reson. Med. 54 (2005) 507-512. doi:10.1002/mrm.20605.

[53] X. Zhang, E.T. Petersen, E. Ghariq, J.B. De Vis, A.G. Webb, W.M. Teeuwisse, J. Hendrikse, M.J.P. Van Osch, In vivo blood T1 measurements at 1.5 T, 3 T, and 7 T, Magn. Reson. Med. 70 (2013) 1082-1086. doi:10.1002/mrm.24550. 
[54] H.J. van de Haar, S. Burgmans, J.F.A. Jansen, M.J.P. van Osch, M.A. van Buchem, M. Muller, P.A.M. Hofman, F.R.J. Verhey, W.H. Backes, Blood-Brain Barrier Leakage in Patients with Early Alzheimer Disease, Radiology. 281 (2016) 527-535. doi:10.1148/radiol.2016152244.

[55] Y.X.J. Wáng, J.-M. Idée, A comprehensive literatures update of clinical researches of superparamagnetic resonance iron oxide nanoparticles for magnetic resonance imaging, Quant. Imaging Med. Surg. 7 (2017) 88-122. doi:10.21037/qims.2017.05.05.

[56] K.M. Donahue, R.M. Weisskoff, D. Burstein, Water diffusion and exchange as they influence contrast enhancement, J. Magn. Reson. Imaging. 7 (1997) 102-110. doi:10.1002/jmri.1880070114.

[57] W. Shin, T.A. Cashen, S.W. Horowitz, R. Sawlani, T.J. Carroll, Quantitative CBV measurement from static T1 changes in tissue and correction for intravascular water exchange., Magn. Reson. Med. 56 (2006) 138-145. doi:10.1002/mrm.20937.

[58] Y.R. Kim, K.J. Rebro, K.M. Schmainda, Water exchange and inflow affect the accuracy of T1-GRE blood volume measurements: implications for the evaluation of tumor angiogenesis, Magn Reson Med. 47 (2002) 1110-1120.

doi:10.1002/mrm.10175.

[59] G.R. Moran, F.S. Prato, Modeling (1H) exchange: an estimate of the error introduced in MRI by assuming the fast exchange limit in bolus tracking, Magn Reson Med. 51 (2004) 816-827. doi:10.1002/mrm.20002.

[60] S. Huang, J.K. Kim, D.N. Atochin, C.T. Farrar, P.L. Huang, J.Y. Suh, S.J. Kwon, W.H. Shim, H. Cho, G. Cho, Y.R. Kim, Cerebral blood volume affects blood-brain barrier integrity in an acute transient stroke model., J. Cereb. Blood Flow Metab. 33 (2013) 898-905. doi:10.1038/jcbfm.2013.27.

[61] J.A. Wells, M.F. Lythgoe, M. Choy, D.G. Gadian, R.J. Ordidge, D.L. Thomas, Characterizing the origin of the arterial spin labelling signal in MRI using a multiecho acquisition approach, J Cereb Blood Flow Metab. 29 (2009) 1836-1845. doi:10.1038/jcbfm.2009.99. 
[62] L. Hirschler, L.P. Munting, A. Khmelinskii, W.M. Teeuwisse, E. Suidgeest, J.M. Warnking, L. van der Weerd, E.L. Barbier, M.J.P. van Osch, Transit time mapping in the mouse brain using time-encoded pCASL, NMR Biomed. 31 (2018) 1-11. doi:10.1002/nbm.3855.

[63] J.P. Wansapura, S.K. Holland, R.S. Dunn, W.S. Ball, NMR Relaxation Times in the HumanBrain at 3.0 Tesla, J. Magn. Reson. Imaging. 538 (1999) 531-538.

[64] E. Cox, P.A. Gowland, Measuring T2 and T2' in the brain at 1.5T, 3T and 7T using a hybrid gradient echo-spin echo sequence and EPI, Proc. Intl. Soc. Mag. Reson. Med. Toronto (2008) 1411. /MyPathway2008/1411.

[65] L.C. Krishnamurthy, P. Liu, F. Xu, J. Uh, I. Dimitrov, H. Lu, Dependence of blood T2 on oxygenation at $7 \mathrm{~T}$ : In vitro calibration and in vivo application, Magn. Reson. Med. 71 (2014) 2035-2042. doi:10.1002/mrm.24868.

[66] J.M. Zhao, C.S. Clingman, M.J. Närväinen, R.A. Kauppinen, P.C.M. Van Zijl, Oxygenation and hematocrit dependence of transverse relaxation rates of blood at 3T, Magn. Reson. Med. 58 (2007) 592-597. doi:10.1002/mrm.21342.

[67] M.J. Silvennoinen, C.S. Clingman, X. Golay, R.A. Kauppinen, P.C.M. Van Zijl, Comparison of the dependence of blood R2 and R2* on oxygen saturation at 1.5 and 4.7 Tesla, Magn. Reson. Med. 49 (2003) 47-60. doi:10.1002/mrm.10355.

[68] J.A. Wells, B. Siow, M.F. Lythgoe, D.L. Thomas, Measuring biexponential transverse relaxation of the ASL signal at 9.4 T to estimate arterial oxygen saturation and the time of exchange of labeled blood water into cortical brain tissue, J. Cereb. Blood Flow Metab. 33 (2013) 215-224. doi:10.1038/jcbfm.2012.156.

[69] D. Le Bihan, E. Breton, D. Lallemand, M.L. Aubin, J. Vignaud, M. Laval-Jeantet, Separation of diffusion and perfusion in intravoxel incoherent motion MR imaging., Radiology. 168 (1988) 497-505. doi:10.1148/radiology.168.2.3393671.

[70] A.C. Silva, D.S. Williams, A.P. Koretsky, Evidence for the exchange of arterial spinlabeled water with tissue water in rat brain from diffusion-sensitized measurements of perfusion., Magn. Reson. Med. 38 (1997) 232-7. doi:10.1002/mrm.1910380211. 
[71] J. Wang, M.A. Fernández-Seara, S. Wang, K.S.S. Lawrence, When Perfusion Meets Diffusion: in vivo Measurement of Water Permeability in Human Brain, J. Cereb. Blood Flow Metab. 27 (2007) 839-849. doi:10.1038/sj.jcbfm.9600398.

[72] K.S. St. Lawrence, D. Owen, D.J.J. Wang, A two-stage approach for measuring vascular water exchange and arterial transit time by diffusion-weighted perfusion MRI, Magn. Reson. Med. 67 (2012) 1275-1284. doi:10.1002/mrm.23104.

[73] J. Wang, D.C. Alsop, H.K. Song, J.A. Maldjian, K. Tang, A.E. Salvucci, J.A. Detre, Arterial transit time imaging with flow encoding arterial spin tagging (FEAST), Magn. Reson. Med. 50 (2003) 599-607. doi:10.1002/mrm.10559.

[74] K. Wengler, L. Bangiyev, T. Canli, T.Q. Duong, M.E. Schweitzer, X. He, 3D MRI of whole-brain water permeability with intrinsic diffusivity encoding of arterial labeled spin (IDEALS), Neuroimage. 189 (2019) 401-414. doi:10.1016/j.neuroimage.2019.01.035.

[75] A.C. Silva, W. Zhang, D.S. Williams, A.P. Koretsky, Estimation of water extraction fractions in rat brain using magnetic resonance measurement of perfusion with arterial spin labeling, Magn. Reson. Med. 37 (1997) 58-68. doi:10.1002/mrm.1910370110.

[76] G. Zaharchuk, A.A. Bogdanov, J.J.A. Marota, M. Shimizu-Sasamata, R.M. Weisskoff, K.K. Kwong, B.G. Jenkins, R. Weissleder, B.R. Rosen, Continuous Assessment of Perfusion by Tagging Including Volume and Water Extraction (CAPTIVE): A steadystate contrast agent technique for measuring blood flow, relative blood volume fraction, and the water extraction fraction, Magn. Reson. Med. 40 (1998) 666-678. doi:10.1002/mrm.1910400504.

[77] H. Beaumont, A. Pearson, M. Van Osch, L. Parkes, Estimation of Water Exchange across the Blood Brain Barrier Using Contrast-Enhanced ASL.", 24th Annu. Meet. Int. Soc. Magn. Reson. Med. (2016).

[78] Z. Lin, Y. Li, P. Su, D. Mao, Z. Wei, J.J. Pillai, A. Moghekar, M. van Osch, Y. Ge, H. Lu, Non-contrast MR imaging of blood-brain barrier permeability to water, Magn. Reson. Med. (2018) 1-14. doi:10.1002/mrm.27141.

[79] E.C. Wong, Vessel-encoded arterial spin-labeling using pseudocontinuous tagging, 
Magn. Reson. Med. 58 (2007) 1086-1091. doi:10.1002/mrm.21293.

[80] J.J.H. Ackerman, C.S. Ewy, N.N. Becker, R.A. Shalwitz, Deuterium nuclear magnetic resonance measurements of blood flow and tissue perfusion employing $2 \mathrm{H} 2 \mathrm{O}$ as a freely diffusible tracer., Proc. Natl. Acad. Sci. U. S. A. 84 (1987) 4099-4102. doi:10.1073/pnas.84.12.4099.

[81] F.N. Wang, S.L. Peng, C.T. Lu, H.H. Peng, T.C. Yeh, Water signal attenuation by D2O infusion as a novel contrast mechanism for1H perfusion MRI, NMR Biomed. 26 (2013) 692-698. doi:10.1002/nbm.2914.

[82] R.J.T. Corbett, A.R. Laptook, E. Olivares, Simultaneous measurement of cerebral blood flow and energy metabolites in piglets using deuterium and phosphorus nuclear magnetic resonance, J. Cereb. Blood Flow Metab. 11 (1991) 55-65. doi:10.1038/jcbfm.1991.6.

[83] H. Igarashi, V.J. Huber, M. Tsujita, T. Nakada, Pretreatment with a novel aquaporin 4 inhibitor, TGN-020, significantly reduces ischemic cerebral edema, Neurol. Sci. 32 (2011) 113-116. doi:10.1007/s10072-010-0431-1.

[84] H. Igarashi, Y. Suzuki, I.L. Kwee, T. Nakada, Water influx into cerebrospinal fluid is significantly reduced in senile plaque bearing transgenic mice, supporting betaamyloid clearance hypothesis of Alzheimer's disease, Neurol. Res. 36 (2014) 10941098. doi:10.1179/1743132814Y.0000000434.

[85] V.J. Huber, H. Igarashi, S. Ueki, I.L. Kwee, T. Nakada, Aquaporin-4 facilitator TGN073 promotes interstitial fluid circulation within the blood-brain barrier: [ $17 \mathrm{O}] \mathrm{H} 2 \mathrm{O}$ JJVCPE MRI study, Neuroreport. 29 (2018) 697-703.

doi:10.1097/WNR.0000000000000990.

[86] K. Kudo, T. Harada, H. Kameda, I. Uwano, F. Yamashita, S. Higuchi, K. Yoshioka, M. Sasaki, Indirect MRI of 170-labeled water using steady-state sequences: Signal simulation and preclinical experiment, J. Magn. Reson. Imaging. 47 (2018) 13731379. doi:10.1002/jmri.25848.

[87] I. Ronen, H. Merkle, K. Ugurbil, G. Navon, Imaging of H217O distribution in the brain 
of a live rat by using proton-detected 170 MRI, Proc. Natl. Acad. Sci. 95 (1998) $12934-12939$.

[88] X.H. Zhu, N. Zhang, Y. Zhang, X. Zhang, K. Ugurbil, W. Chen, In vivo 170 NMR approaches for brain study at high field, NMR Biomed. 18 (2005) 83-103. doi:10.1002/nbm.930.

[89] I. Ronen, J.H. Lee, H. Merkle, K. Ugurbil, G. Navon, Imaging H2/17O distribution in a phantom and measurement of metabolically produced $\mathrm{H} 2 / 17 \mathrm{O}$ in live mice by proton NMR, NMR Biomed. 10 (1997) 333-340. doi:10.1002/(SICI)10991492(199710)10:7<333::AID-NBM465>3.0.CO;2-E.

[90] K.K. Kwong, A.L. Hopkins, J.W. Belliveau, D.A. Chesler, L.M. Porkka, R.C. McKinstry, D.A. Finelli, G.J. Hunter, J.B. Moore, R.G. Barr, B.R. Rosen, Proton NMR imaging of cerebral blood flow using H2170, Magn. Reson. Med. 22 (1991) 154-158. doi:10.1002/mrm.1910220116.

[91] H. Igarashi, M. Tsujita, I.L. Kwee, T. Nakada, Water influx into cerebrospinal fluid is primarily controlled by aquaporin-4, not by aquaporin-1: 170 JJVCPE MRI study in knockout mice, Neuroreport. 25 (2014) 39-43. doi:10.1097/WNR.0000000000000042.

[92] A.L. Hopkins, E.M. Haacke, J. Tkach, R.G. Barr, C.B. Bratton, Improved sensitivity of proton MR to oxygen-17 as a contrast agent using fast imaging: Detection in brain, Magn. Reson. Med. 7 (1988) 222-229. doi:10.1002/mrm.1910070210.

[93] W.A. Anderson, J.T. Arnold, Proton relaxation times in H2O D2O mixtures, Phys. Rev. 101 (1956) 511-512. doi:10.1103/PhysRev.101.511.

[94] Y. V Tiwari, J. Lu, Q. Shen, B. Cerqueira, T.Q. Duong, Magnetic resonance imaging of blood-brain barrier permeability in ischemic stroke using diffusion-weighted arterial spin labeling in rats, J. Cereb. Blood Flow Metab. 37 (2017) 2706-2715. doi:10.1177/0271678X16673385.

[95] X. Shao, S.J. Ma, M. Casey, L. D’Orazio, J.M. Ringman, D.J.J. Wang, Mapping water exchange across the blood-brain barrier using 3D diffusion-prepared arterial spin labeled perfusion MRI, Magn. Reson. Med. (2018) 1-15. doi:10.1002/mrm.27632. 
[96] J.A. Palomares, S. Tummala, D.J.J. Wang, B. Park, M.A. Woo, D.W. Kang, K.S.S. Lawrence, R.M. Harper, R. Kumar, Water Exchange across the Blood-Brain Barrier in Obstructive Sleep Apnea: An MRI Diffusion-Weighted Pseudo-Continuous Arterial Spin Labeling Study, J. Neuroimaging. 25 (2015) 900-905. doi:10.1111/jon.12288.

[97] Y. Zhang, M. Poirier-Quinot, C.S. Springer, J.A. Balschi, Active trans-plasma membrane water cycling in yeast is revealed by NMR, Biophys. J. 101 (2011) 28332842. doi:10.1016/j.bpj.2011.10.035.

[98] R. Bai, C.S. Springer, D. Plenz, P.J. Basser, Brain active transmembrane water cycling measured by MR is associated with neuronal activity, Magn. Reson. Med. (2018) 1-16. doi:10.1002/mrm.27473.

[99] R. Bai, C.S. Springer, D. Plenz, P.J. Basser, Fast, Na+/K+pump driven, steady-state transcytolemmal water exchange in neuronal tissue: A study of rat brain cortical cultures, Magn. Reson. Med. 79 (2018) 3207-3217. doi:10.1002/mrm.26980.

[100] Y. Ohene, I.F. Harrison, P. Nahavandi, O. Ismail, E. V. Bird, O.P. Ottersen, E.A. Nagelhus, D.L. Thomas, M.F. Lythgoe, J.A. Wells, Non-invasive MRI of brain clearance pathways using multiple echo time arterial spin labelling: An Aquaporin-4 study, Neuroimage. (2018). doi:10.1016/J.NEUROIMAGE.2018.12.026.

[101] H. Igarashi, M. Tsujita, Y. Suzuki, I.L. Kwee, T. Nakada, Inhibition of aquaporin-4 significantly increases regional cerebral blood flow, Neuroreport. 24 (2013) 324-328. doi:10.1097/WNR.0b013e32835fc827.

[102] D. Atochin, M. Litvak, S. Huang, Y.R. Kim, P. Huang, Role of eNOS in water exchange index maintenance-MRI studies, J. Phys. Conf. Ser. 886 (2017). doi:10.1088/1742-6596/886/1/012002.

[103] S.I. Rapoport, Osmotic opening of the blood-brain barrier: Principles, mechanism, and therapeutic applications, Cell. Mol. Neurobiol. 20 (2000) 217-230. doi:10.1023/A:1007049806660.

[104] C.N. Hall, C. Reynell, B. Gesslein, N.B. Hamilton, A. Mishra, B.A. Sutherland, F.M. O’Farrell, A.M. Buchan, M. Lauritzen, D. Attwell, Capillary pericytes regulate cerebral 
blood flow in health and disease., Nature. 508 (2014) 55-60.

doi:10.1038/nature13165.

[105] I.R. Cameron, H. Davson, M.B. Segal, The effect of hypercapnia on the blood-brain barrier to sucros in the rabbit, J. Biol. Med. 42 (1970) 241-247.

[106] C.A.. Evans, J.M. Reynolds, M.L. Reynolds, N.. Saunders, The effect of hypercapnia on a blood-brain barrier mechanism in foetal and new-born sheep, J. Physiol. 255 (1976) 701-714.

[107] M.D. Herbst, J.H. Goldstein, A review of water diffusion measurement by NMR in human red blood cells., Am. J. Physiol. 256 (1989) C1097-104. doi:10.1152/ajpcell.1989.256.5.C1097.

[108] D.M. Yang, J.E. Huettner, G.L. Bretthorst, J.J. Neil, J.R. Garbow, J.J.H. Ackerman, Intracellular water preexchange lifetime in neurons and astrocytes, Magn. Reson. Med. 79 (2018) 1616-1627. doi:10.1002/mrm.26781.

[109] E. Syková, C. Nicholson, Diffusion in Brain Extracellular Space, Physiol. Rev. 88 (2008) 1277-1340. doi:10.1152/physrev.00027.2007.

[110] J. Andrasko, Water diffusion permeability of human erythrocytes studied by a pulsed gradient NMR technique, BBA - Gen. Subj. 428 (1976) 304-311. doi:10.1016/03044165(76)90038-6.

[111] M. Nilsson, J. Lätt, D. Van Westen, S. Brockstedt, S. Lasič, F. Ståhlberg, D. Topgaard, Noninvasive mapping of water diffusional exchange in the human brain using filter-exchange imaging, Magn. Reson. Med. 69 (2013) 1573-1581. doi:10.1002/mrm.24395.

[112] G.T. Manley, M. Fujimura, T. Ma, N. Noshita, F. Filiz, A.W. Bollen, P. Chan, A.S. Verkman, Aquaporin-4 deletion in mice reduces brain edema after acute water intoxication and ischemic stroke., Nat. Med. 6 (2000) 159-163. doi:10.1038/72256.

[113] S. Eriksson, K. Elbing, O. Söderman, K. Lindkvist-Petersson, D. Topgaard, S. Lasič, NMR quantification of diffusional exchange in cell suspensions with relaxation rate differences between intra and extracellular compartments, PLoS One. 12 (2017) 1- 
18. doi:10.1371/journal.pone.0177273.

[114] C. Badve, A. Yu, M. Rogers, D. Ma, Y. Liu, M. Schluchter, J. Sunshine, M. Griswold, V. Gulani, Simultaneous T1 and T2 Brain Relaxometry in Asymptomatic Volunteers Using Magnetic Resonance Fingerprinting, Tomography. 1 (2015) 136-144. doi:10.18383/j.tom.2015.00166.

[115] Y. Ohene, I.F. Harrison, P. Nahavandi, O. Ismail, E. V. Bird, O.P. Ottersen, E.A. Nagelhus, D.L. Thomas, M.F. Lythgoe, J.A. Wells, Non-invasive MRI of brain clearance pathways using multiple echo time arterial spin labelling: An Aquaporin-4 study, Neuroimage. (2018). doi:10.1016/J.NEUROIMAGE.2018.12.026.

[116] X. Shao, S.J. Ma, L. Cao, M. Casey, J.M. Ringman, D.J. Wang, Measuring Water Exchange Across Blood Brain Barrier in Elderly Subjects By Diffusion Weighted Pseudo-Continuous Arterial Spin Labeling, Alzheimer's Dement. 14 (2018) P835P836. doi:10.1016/j.jalz.2018.06.1060.

[117] P.W. Hales, C. a Clark, Combined arterial spin labeling and diffusion-weighted imaging for noninvasive estimation of capillary volume fraction and permeabilitysurface product in the human brain, J. Cereb. Blood Flow Metab. 33 (2012) 67-75. doi:10.1038/jcbfm.2012.125.

[118] Z. Lin, Y. Li, P. Su, D. Mao, Z. Wei, J.J. Pillai, A. Moghekar, M. van Osch, Y. Ge, H. Lu, Non-contrast MR imaging of blood-brain barrier permeability to water, Magn. Reson. Med. 80 (2018) 1507-1520. doi:10.1002/mrm.27141. 


\section{Glossary of abbreviations}

ASL - arterial spin labelling

AD - Alzheimer's disease

AQP1/AQP 4 - aquaporin water channels 1 and 4

BBB - Blood brain barrier

CAPTIVE - Continuous assessment of perfusion by tagging including volume and water extraction

CBF - cerebral blood flow

CBV - cerebral blood volume

DCE-MRI - dynamic contrast enhanced MRI

EPI - echo planar imaging

GLUT1 - Glucose transporter 1

IDEALS - Intrinsic diffusivity encoding of arterial labelled spins

IR - inversion recovery

IVIM - Intravoxel incoherent motion

MCAo - middle cerebral artery occlusion

MFAME-MRI - multi-flip angle multi echo MRI

MS - multiple sclerosis

NMR - nuclear magnetic resonance

PET - positron emission tomography

PLD - post-labelling delay

PS - permeability surface area product

PSF - point spread function

RARE - Rapid imaging with refocussed echoes

SNR - signal to noise ratio

SPA - single pass approximation model

SPGR - spoiled gradient echo

SPION - Super paramagnetic iron oxide nanoparticle

SSS - superior sagittal sinus

$\mathrm{TR}$ - repetition time

TE - echo time

TJ - tight junction

WEI -water exchange index 
DW-MRI - Diffusion-weighted MRI

OSA - obstructive sleep apnea 